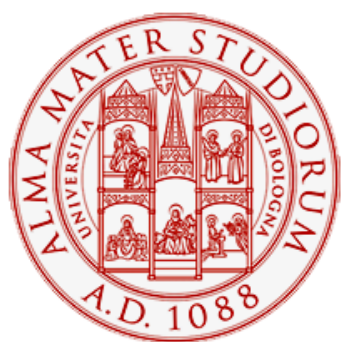

Alma Mater Studiorum - Università di Bologna DEPARTMENT OF ECONOMICS

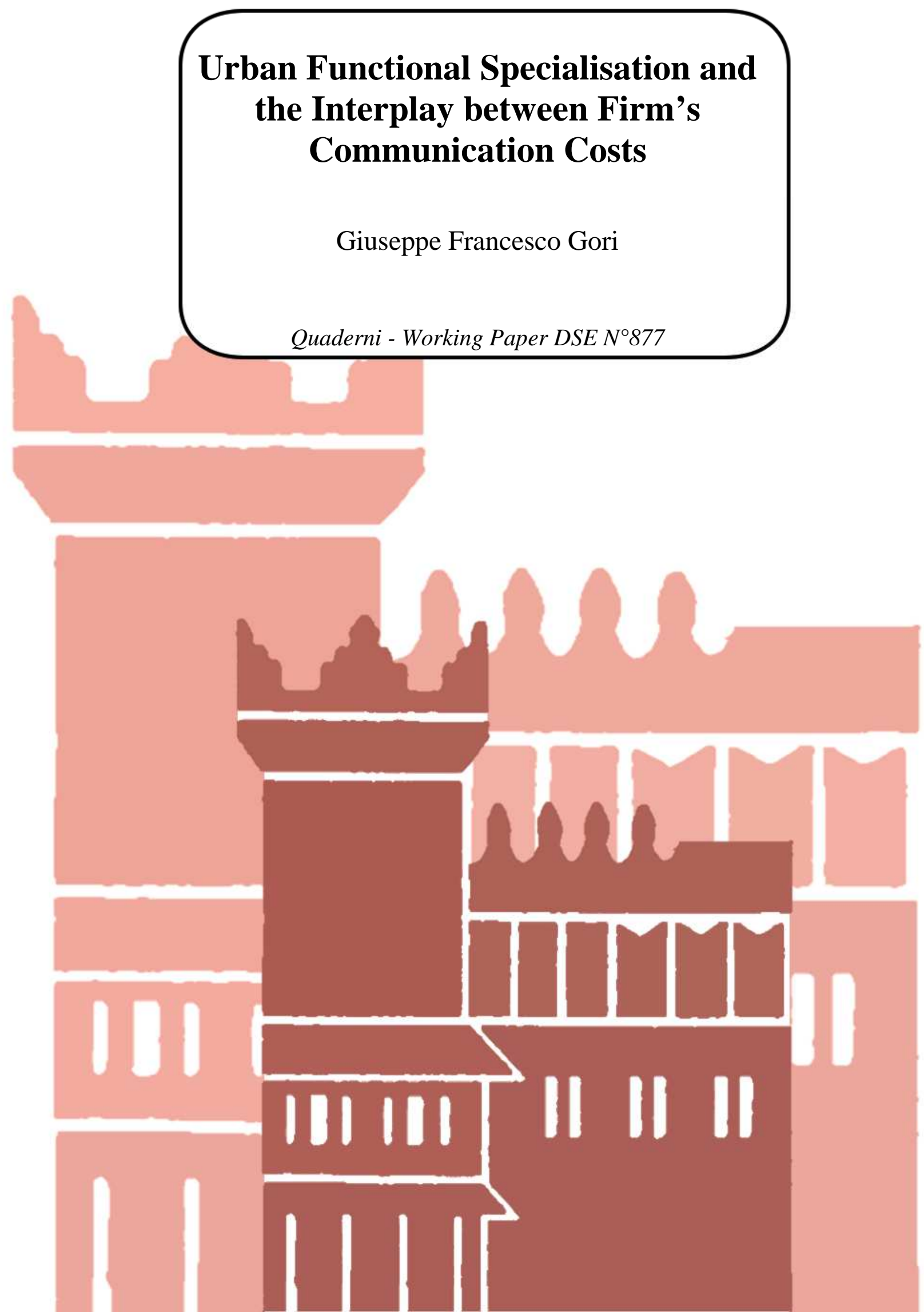




\title{
Urban Functional Specialisation and the Interplay between Firm's Communication Costs*
}

\author{
Giuseppe Francesco Gori ${ }^{\dagger}$
}

April 11, 2013

\begin{abstract}
This paper focuses on the functional specialisation of a system of cities, with particular attention to the role and the formation process of secondary business centers. At the european level, the latters can be identified in the large number of regional capitals, and properly defined as cities hosting both headquarters of multi-location firms and providers of standard non-tradable business services (SBS). I present a theoretical model in which the changes in urban system's degree of functional specialisation are linked to (i) firms' organisational choices, since firms decide whether splitting into headquarter and production plant or remaining integrated in a single establishment and to (ii) firms' location decision with regards to the proximity with the tradable advanced business services providers. I model two types of communication costs, one between headquarters and advanced tradable business services providers (ABS) and one between headquarters and production plants. The interplay between the two types of communication costs is shown to have effects on the transition process from an "integrated" urban system where each city hosts every different functions to a "functionally specialised" urban system where each city is either a primary business center (hosting ABS), a secondary business centers (SBS) or a pure manufacturing city and all this city-types coexist in equilibrium. In particular, I find that maximum functional specialisation of the urban system turns out to be feasible only if firms face a very high share of the total costs represented by their heaquarter spending.
\end{abstract}

JEL Numbers: R30, L23, R12

Keywords: functional specialisation, cities, headquarters, business services

\footnotetext{
${ }^{*}$ I would like to thank Piero Tedeschi, Paolo Epifani and Gianmarco Ottaviano for helpful comments and suggestions on earlier drafts. The usual disclaimer applies.

${ }^{\dagger}$ Department of Economics, University of Bologna. Strada Maggiore 45, 40125 Bologna, Italy. Email: giuseppe.gori@unibo.it.
} 


\section{Introduction}

A large part of the existing theoretical literature on systems of cities depicts the spatial economy as exclusively composed by two urban typologies which may or not coexist in equilibrium: large and sectorally diversified cities hosting a highly educated workforce - which is occupied in managing tasks or in the service sector - and small and sectorally specialised manufacturing cities. $^{1}$

However, as a matter of fact, economies worldwide encompass different and more complex types of urban configurations. In particular, national urban systems are progressively melting in supranational/international systems, where even some large national capitals - which can be broadly read as business and policy-decision centers - are relegated to a secondary functional role, while more sophisticated business services, finance, insurance, real estate (the so-called FIRE) sectors (henceforth advanced business services, ABS), gather in a little bunch of metropolis (or central business centers, henceforth PBC).

These secondary urban centers, whose size may be characterised by a high variance, are not production-intensive nor specialised in the service sector, and, at the same time, sectorally diversified with respect to manufacturing. Moreover, they represent a large subset of the urban universe which seemingly includes regional capitals. The latters often compete at some federal level for subsidies and grants. This may be actually puzzling, unless we give them recognition of a specific role which may be linked to non-economic dimensions, such as political or historical ones. As an alternative to these "exogenous" explanations we may think to a specific economic functional role. In order to tackle the problem, it is useful to observe that these centers are often seen by firms, especially by those belonging to manufaturing sectors, as the right places for locating their headquarters.

We could then argue why this happens referring to what the recent empirical literature suggests as headquarters' location determinants. According to Strauss-Kahn and Vives (2009), in fact, the managers benefit from the presence of good airport facilities, low corporate taxes, amenities, such as recreational services, low average wages and high levels of business services and agglomeration of headquarters in the same sector of activity. As further stressed by Lovely et al. (2005), the latter determinant is explicable by considering that the co-location of headquarters reduces the cost of the informations relative to foreign export makets or, more in general, as pointed out by Davis and Henderson (2007), benefits are to be accounted to an own sector external scale effect. ${ }^{2}$ However, these authors find out that scale effects alone cannot explain high concentrations of headquarters in some larger cities, and diversity of local service inputs (i.e. sharing differentiated standard business banking or equipment leasing services) is claimed as an additional force leading the agglomeration process. Finally, for Aarland et al. (2007) the firms are attracted by the availability of highly educated white collars ${ }^{3}$ while the latters (managers) benefit from a low degree of noise and pollution with respect to pure manufacturing cities. $^{4}$

An additional element to be accounted for, is the fact that regional and secondary national

\footnotetext{
${ }^{1}$ With regards to this issue, see Duranton and Puga (2001).

${ }^{2}$ See also Jacobs et al. (2013).

${ }^{3}$ On the contrary Strauss-Kahn and Vives (2009) find that the level of human capital, as proxied by the percent of labor force with a bachelor degree is highly correlated with the level of business services and not significant.

${ }^{4}$ See also Defever $(2006,2012)$.
} 
capital cities are generally well connected with large physical communication (point or network) infrastructures such as highways, railways and airports. With regards to the latter point, it is worth to recall the importance of the distance-managing cost for firm's spatial organisation choice: according to the level of this cost firms may decide whether to split up into production plants and headquarters (multi-location organisational form) or to keep establishments together (integrated organisational form). As far as this managing cost is a function of the urban accessibility, it also leads headquarters' localisation choices: ceteris paribus, fims will choose to locate headquarters in the best connected city, in order to keep the managing side relatively close to the production one in a way that minimise the cost of coordinating the production at distance. The dematerialisation of this cost component may, on a side, imply a cost reduction - which leads to a proliferation of the multi-locational scheme - and on the other side, separate the location problem from the infrastructural endowment of cities, arguably linking it to other variables such as the local cost of inputs.

At the same time, since advanced business services are an undoubtedly significant component of headquarters' cost function, their tradability also necessarily affects headquarters' location choices. The regional capitals will then become attractive the more the headquarters will be able to buy sophisticated business services from distance. Since the latters are essentially immaterial, their tradability exclusively involves a transaction/communication cost, that is, the ability of business services providers to correctly understand and face firms' problems from a distant place.

What stated so far would suggest that the dynamics of the managing cost at distance, and that of the transaction cost between the firm's headquarter and the advanced business services providers are key determinants of firms' organisational and localisation choices. Moreover, this could imply that highly functionally specialised urban configurations where "manufacturing", "headquarters" and "advanced/tradable business services" cities coexist, may be the result of the exploiting of localisation incentives at the firm level.

Accordingly, the theoretical model on functional specialisation in systems of cities that I propose tries to fit the dynamics of urban configuration transformation by assigning a predominant role to changes in the spatial organisation of firms. I formally rely on the Duranton and Puga (2005) general equilibrium model, with Henderson-type floating-island cities and agglomeration economies in local (standard) business services and intermediate goods' producers. According to their work, the decline of managing/communication costs over the last decades is the main force delivering the transition from a functionally diversified urban environment to a specialised one.

My contribution retains this overall interpretation by postulating an even extended influence of the communication costs dynamics on the spatial and functional configuration of urban systems. In fact, the organisational choice made by firms is now not only affected by the level of communication costs between headquarters and production plants but also by that borne by headquarters in order to exchange information with the advanced business services providers.

This lets firms decide concerning the localisation of headquarters with respect to business service providers: firms would move headquarters away from business services providers only if the additional transaction costs they face in buying business services from distance is low enough. The interaction between the additional managing cost due to firms internal spatial separation and the additional transaction cost due to firms location decision determines the conditons under which the different urban configurations are feasible in equilibrium. Both costs 
are intended as extra headquarter requirements in case of spatial separation.

While business services' characterisation has been substantially disregarded in the literature, only a few among the past theoretical works, apart from the above cited Duranton and Puga (2005), explicitly deal with the effects of communication costs' dynamics on the spatial organisation of consumers/workers and firms at urban system's level. In particular, Ioannides et al. (2008) make use of the Rossi-Hansberg and Wright (2007) dynamic model of cities and growth in order to analyze the effects of ICT on the distribution of city-size. Authors find that increases in the number of telephone lines per-capita lead to a more concentrated distribution of city sizes and so to a more dispersed distribution of economic activities in the space (a steeper Zipf curve). In other words, an improvement in ICT corresponds to a decrease in the number of large cities. This is substantially due to the fact that improvements in ICT reduce externalities generated by human capital and employment in an industry and, in so doing, reduce the incentives for economic activities to agglomerate.

Rossi-Hansberg et al. (2009) propose a theory of urban structure that emphasises the location and the internal structure decision of firms in the light of my model so as firms can decide whether spatially separating headquarters and operation plants or keeping them integrated; however this is only possible in different regions of the city and no system of cities is modelled. Moreover, authors do not view changes in communication technology as the force underlying changes in urban structure but theyinstead identify the population growth as the key process. Their model is able to replicate several empirical regularities regarding the evolution of the urban structures in the largest U.S. metropolitan areas in the $80 \mathrm{~s}$, such as an increase in residents at city centers and city boundaries, a reduction in the share of employment and residents in the central region of cities, a concentration of managers relative to non-managers at the center, an increase in establishments in both areas of the city (city center and edge), a decrease in establishment shares at the center, a decline in establishment size both at the center and at the edge of cities.

Another interesting contribution is the theoretical work by Cavailhés et al. (2007) which, in order to rationalise urban polycentricity, points on the interplay between three types of spatial frictions: trade, commuting and communication costs. They develop a two-region model in which, for low commuting and communication costs, intra-city secondary centers may arise to accommodate part of the total urban employment and, in so doing, alleviate the burden of urban costs without losing those benefits which stem from agglomeration. In authors' view, this allows the larger cities to maintain their predominance even in the presence of fairly low (inter-regional) trade costs which may in principle favor a relocation of the workforce from the larger and more dense urban areas to the smaller ones. Fujita and Thisse (2006) set up a model of firm fragmentation in an international framework with trade costs, their main focus is on the redistributive effects of the process of fragmentation and/or integration triggered, again, by the dynamics of communication costs levels. Finally, the work from Wen-Chi (2012) focuses on the inshoring of business support services by firms, providing evidences of a process for which these activities are increasingly shifting away from big cities to smaller ones and separating from managerial jobs. The author provides an explanation based on new ICT technology development, which increases marginal productivity of workers employed in business services activities even in smaller or peripheral areas.

Turning back to empirical works, Aarland et al. (2007) find that light manufacturing industries are more likely to spatially separate managing from production and that for economies 
characterised by a significant number of firms belonging to the non-service sector, with plants in three or more countries, the probability of having a Central Administrative Office is very low. The latter result is well fitted by my model since I show that the spatial equilibrium configuration encompassing integrated firms located in a different city with respect to business services providers, no further reduction of the remote managing cost can lead to a headquarters and plants separation, except for the case in which firms are characterised by a very high share of total costs represented by labor directly employed in their headquarters. ${ }^{5}$ The same authors point out on two more aspects which are worth of being mentioned: the first one is that for headquarters, outsourcing is not properly replacing in-house production since headquarters that outsource legal services, accounting or advertising, have a 2-3-fold higher percentage of employees working internally at that function; the second one is that between the US counties analyzed, functional specialisation in headquarter activity result to be more frequent in middensity counties, while larger ones are less headquarters centers than business services centers exporting services to the rest of the country. These results reinforce the idea that headquarters activity and highly specialised business services providers are not spatially inextricable. Accordingly, Diacon and Klier (2003) document a trend of dispersion of headquarters from large to medium-sized, fast growing metropolitan areas, especially for what concerns manufacturing firms. The same point is made up by Henderson and Ono (2008) which show how, across US counties, the relative concentration of headquarters in medium and smaller size cities contrasts with the geographical distribution of business service industries; headquarters are not disproportionately concentrated in large metropolitan areas as commonly thought. However, the way Audretsch et al. (2011) interpret these latter results is opposite to mine. They argue that a considerable number of manufacturing firms do not choose to geographically split their facilities and, consequently, that headquarters in medium-size cities belong to integrated firms, while I suppose that the dispersion of headquarter is due to a further functional specialisation: while advanced business services providers undoubtedly benefit from agglomerating in large metro areas, headquarters may find regional capitals a better place. Finally Ono $(2003,2007)$ uncover the phenomenon of outsourcing business services by Central Administrative Offices; he finds that firms may benefit by separating $\mathrm{CAO}$ from production plants to locate them in larger and thicker local markets and rely on them to save on outsourced business services.

The remainder of the paper is organised as follows. The model is presented in section 2 while section 3 characterise the equilibrium types and sizes of cities. Section 4 identifies the relevant communication costs thresholds and discusses the results. Section 5 concludes.

\section{The model}

I adopt a general equilibrium framework, where consumers/workers inelastically supply one unit of labor and can choose between occupations and cities while final goods firms belonging to one of the $m$ sectors existing in the economy, produce a sectorally homogeneous good, which is freely traded across cities. The spatial equilibrium is defined by the sizes and types of the existing cities, where the types are defined on the basis of the degree of sectoral and functional specialisation of the workforce living in the city.

\footnotetext{
${ }^{5}$ So, arguably, except for the case of multi-location firms belonging to the service sector.
} 


\subsection{Preferences}

Utility function of the representative consumer is defined over a composite final good $M$ which is aggregation of the $m$ final goods produced in the economy. Each of this goods enters with equal shares, in a Cobb-Douglas fashion, in the utility function:

$$
U=f(M) \quad \text { where } \quad M=\prod_{h=1}^{m}\left(x^{h}\right)^{1 / m} .
$$

As in the standard urban economics literature, no measure of the distance between cities is included in the analysis, that is, cities are intended as "floating islands". In other words, there are no transport costs in the market of the final good, nor workers' relocation costs. ${ }^{6}$ This implies that the consumer/worker's location choice may affect her utility uniquely via her (nominal) income. The indirect utility of a consumer working in occupation $h$ in city $i$ then writes as:

$$
V_{i}=\frac{e_{i}^{h}}{P}
$$

where the price index $P$ for the composite final good is the aggregation of sectoral prices:

$$
P=\prod_{h=1}^{m}\left(P^{h}\right)^{1 / m}
$$

while $e_{i}^{h}$ denotes consumption expenditure of an individual living in city $i$ with occupation $h^{7}$ :

$$
e_{i}^{h}=f\left(w_{i}^{h}, T_{i}^{h}, R_{i}, C C_{i}\right),
$$

where the positive determinants are represented by $w_{i}^{h}$, the wage of an individual living in city $i$ with occupation $h$, and $T_{i}^{h}$, a monetary transfer provided by the city government (see below, section 3), while the total commuting costs $C C_{i}$ borne by the consumer/worker and the land rent $R_{i}$, both functions of the consumer location within the city, are the negative determinants. According to the literature, the latters can be addressed as urban costs.

The maximisation of own consumption expenditure by the individuals determines equilibrium city size and, obviously, involves the city choice made by the individuals as well as their location choice within city.

By choosing a city, individuals choose a nominal wage and a level of transfers. Moreover, since the space between cities is not modelled here, the choice of the city is formally equivalent to the choice of the city-type, where, again, the types are defined over the set of sectoral and functional characteristics rather than according to spatial fetaures (such as physical relative distance). ${ }^{8}$ Then, location inside the city is the sole proper spatial control variable of individuals' income. Focusing on the latter amounts to defining the urban internal spatial structure.

\subsection{City structure}

Each city is composed by a Central Business District (henceforth CBD), where every economic activity takes place, and a surrounding residence area of unit length. Residents necessarily

\footnotetext{
${ }^{6}$ See Fujita and Mori (1999) and Fujita et al. (1999) for a NEG approach to the systems of cities in which trade costs between cities are formally taken into account.

${ }^{7}$ See below for a definition of possible occupations.

${ }^{8}$ See below for a complete description of the city types of the economy.
} 
commute to the CBD and, in so doing, lost a fraction of their work supply equal to $2 \tau$ times the distance of their residence from the $\mathrm{CBD}$, that is $z$, so that:

$$
C C_{i}=2 \tau z \cdot w_{i}^{h}
$$

In this sense, $\tau$ must be intended as an iceberg commuting cost. Since lot size is assumed to be fixed, choosing a location $z$ within the city is equivalent to choosing the level of urban $\operatorname{costs}^{9}$ to maximise the net income, given the wage and the amount of monetary transfers.

$$
e_{i}^{h}(z)=w_{i}^{h}(1-2 \tau z)-R_{i}(z)+T_{i}^{h} .
$$

The residents which earn the same wage, thus facing the same opportunity cost of commuting time, will have the same bid-rent function and the same willingness to pay for land. Perfect arbitrage ensures that at residential equilibrium they'll end up with the same level of the urban costs so that they will necessarily sort according to their wage, with better paid workers located close to the CBD.

Moreover, at the residential equilibrium, none of the city residents will have the incentive to move from chosen $z$ : high paid workers and low paid ones will face a different composition but the same level of urban costs. I call $L_{i}$ the city size (i.e. the number of its residents), then total land rent is the integral of land rent function over the unit length city:

$$
R_{i}=\int_{-L_{i} / 2}^{L_{i} / 2} R_{i}(z) d(z)
$$

where right and left sides of the city are symmetric and accommodate half of the total city population $L_{i} / 2$; since each resident consumes a single lot of space this is equivalent to saying that $L_{i} / 2$ represents the maximum distance from the CBD, or the city edge.

\subsection{Technology}

In order to characterise the remaining determinants of individual consumption expenditure $e_{i}^{h}$, I need to move to the supply side of the model. ${ }^{10}$ Final good firms buy from two different types of input suppliers, each one specific to one of their facilities. The final good firms' technology, in fact, combines a headquarter and a production plant component (henceforth, respectively, HQ and PP) so that the Cobb-Douglas production function can be written as:

$$
x^{h}=\left(x_{h q}^{h}\right)^{\eta}\left(x_{p p}^{m+h}\right)^{1-\eta}
$$

where $x^{h}$ denotes output of a firm belonging to sector $h$ with $h=1, \ldots, m$, while $x_{h q}^{h}$ and $x_{p p}^{m+h}$ are, respectively the quantities of HQ's and PP's service inputs. ${ }^{11}$ Unit production cost function

\footnotetext{
${ }^{9}$ In this sense we do not have here the standard result of the equilibrium population density decreasing from the the CBD to the urban fringe: consumers/residents cannot trade more space for housing against a lower accessibility to the CBD given fixed lot size. This also implies that the land rent at the city edges is not zero; in the model it is thus normalised to zero without loss of generality.

${ }^{10}$ This does not formally encompasses any localisation economy for the firms which produce final goods. Moreover, since the market is perfectly competitive and each of these firms earns zero profits in equilibrium, the agglomeration forces of the model, in the light of Abdel-Rahman and Fujita (1990), are represented by localisation economies á la Ethier (1982), that is, aggregate increasing returns arise from the productive advantages of sharing a large number of local varieties of intermediate inputs suppliers (see below).

${ }^{11}$ Superscript $m+h$ is always assigned to variables which refers to PPs while those referring to HQs are indexed with $h$ with $h=1, \ldots, m$.
} 
thus writes as:

$$
c^{h}=\left(H^{h}\right)^{\eta}\left(Q^{m+h}\right)^{1-\eta}
$$

where $H^{h}$ represents the HQ's sub-cost while $Q^{m+h}$ the PP's one.

Each of the firm's facilities (HQs and PPs) use specific intermediate inputs: in the case of HQs these are business services (banking and legal services, advertising), and these outsourced business services and HQs specific labor force (managers) enter the Cobb-Douglas production function with shares $\mu$ and $1-\mu$ respectively. The relative sub-cost function is therefore specified as:

$$
H^{h}=\left(w^{h}\right)^{\mu}\left(Q^{0}\right)^{1-\mu}
$$

where $w_{i}^{h}$ is the unitary labor cost in city $i$ and sector $h$ while $Q_{i}^{0}$ is business services' composite price index. ${ }^{12}$ For what concerns the PPs, the only inputs which enter in the sub-production function are the sector specific intermediates, which can be broadly read as semi-processed products or technical components of the final good. The PP sub-cost function $Q_{i}^{m+h}$ therefore coincides with the composite price index for intermediates.

I can thus say that the model encompasses $2 m+1$ occupations for workers: workers may be directly occupied in the headquarters of sector $h$, in the production of business services, or in the production of intermediates specific to sector $h$.

The mass of varieties of business services produced in city $i$ is endogenously determined and indicated as $s_{i}^{0}$ and all varieties enter in the headquarters' technology with constant elasticity of substitution $(\theta+1) / \theta$, where $\theta>0$. The relevant price index of business services can therefore be expressed as:

$$
Q_{i}^{0}=\left[\int_{0}^{s_{i}^{0}}\left[q_{i}^{0}(k)\right]^{-1 / \theta}\right]^{-\theta}
$$

where $q_{i}^{0}(k)$ is the price of variety $k$ of the business services produced in city $i$. While the cost function of a firm producing a single variety is:

$$
C_{i}^{0}(k)=\left[\alpha^{0}+\beta^{0} y_{i}^{0}(k)\right] w_{i}^{0}
$$

where $y_{i}^{0}(k)$ denotes firm's output, $\alpha$ and $\beta$ respectively denotes the fixed and variable labor requirements. ${ }^{13}$

Since the cost function relative to a single variety involves a fixed labor requirement and since all the varieties of both business service suppliers and intermediate producers enter in the final good production function with the same constant elasticity of substitution (respectively $(\theta+1) / \theta$ and $(\epsilon+1) / \epsilon)$, the more labor is employed in the specific intermediate sector or in the business service sector, the more varieties will result in equilibrium and will therefore lower the correspondent composite price.

The process of specialisation is limited by the size of the labor market $l_{i}$ as well as by the presence of a fixed component of the unit labor requirement $\alpha$. The equilibrium number of varieties also

\footnotetext{
${ }^{12}$ The superscript 0 always refers to the business services sector. Note that the fact that the superscript $h=0$ is associated with business services' variables is due to a specific assumption of the model: while the intermediates used by the PPs are sector-specific, the same business services are used by the HQs in all sectors.

${ }^{13}$ To obtain corresponding definitions for intermediates entering PPs production function is sufficient to replace superscript 0 with $m+h$ and $\theta$ with $\epsilon>0$.
} 
rises with the degree of product differentiation which characterise the sector (higher $\theta, \epsilon$ ). This effect results clearer if we express the production plant and headquarter sub-cost functions as: ${ }^{14}$

$$
\begin{cases}Q_{i}^{m+h} & =\left(l_{i}^{m+h}\right)^{-\epsilon} w_{i}^{m+h} \\ Q_{i}^{0} & =\left(l_{i}^{0}\right)^{-\theta} w_{i}^{0}\end{cases}
$$

Where $l_{i}^{m+h}$ and $l_{i}^{0}$ represent the net labour units available for production in city $i .^{15}$ The degree of localisation economies, that is the increasing returns at the sector-city level ${ }^{16}$ is increasing with $\epsilon$ and $\theta$. Since $Q_{i}^{0}$ and $Q_{i}^{m+h}$ enter into the Cobb-Douglas production function of HQs and final good firms, it is useful to define $\sigma=\theta(1-\mu)$, and $\gamma=\eta \sigma+(1-\eta) \epsilon$ where $\sigma$ and $\epsilon$ indicate the localisation economies for business services and intermediates while $\gamma$ indicates the average localisation economies. These parameters may thus be interpreted as a direct measure of the elasticities of the local sectoral productivities to the sector specific workforce: the higher $\sigma$ and $\epsilon$, the stronger will be the negative effect of a marginal increase in the local workforce on the relevant price index of intermediate inputs.

Since both HQs and PPs have a physical location ${ }^{17}$, the final good entrepreneurs belonging to different sectors face the same organisational problem that is choosing between a spatially integrated or multi-location organisational form, but they also face a location problem, that is choosing to locate headquarters in the same city where advanced business services (ABS) are located (the PBC), or in a different city. In fact, as already pointed out in section 1, differently from the standard business services (SBS) and the intermediates, ABS are tradable, in that HQs can make use of ABS provided by firms located in a different city by facing a communication cost. Correspondingly, there are four possible cost functions for the firm which belongs to the sector $h$, and has its HQ in the city $i:^{18}$

1. Integrated Firms in the PBC:

$$
C_{i, i, i}^{h}=\left(H_{i, i, i}^{h}\right)^{\eta}\left(Q_{i}^{m+h}\right)^{1-\eta} x_{i, i, i}^{h}=\left[\left(w_{i}^{h}\right)^{\mu}\left(Q_{i}^{0}\right)^{1-\mu}\right]^{\eta}\left(Q_{i}^{m+h}\right)^{1-\eta} x_{i, i, i}^{h} ;
$$

2. Integrated firms, outside the PBC:

$$
C_{i, i, z}^{h}=(K)^{\eta} \cdot\left(H_{i, i, i}^{h}\right)^{\eta}\left(Q_{i}^{m+h}\right)^{1-\eta} x_{i, i, z}^{h} ;
$$

3. Multi-location firms with $\mathrm{HQ}$ in the PBC:

$$
C_{i, j, i}^{h}=(\rho)^{\eta} \cdot\left(H_{i, i, i}^{h}\right)^{\eta}\left(Q_{i}^{m+h}\right)^{1-\eta} x_{i, j, i}^{h} ;
$$

4. Multi-location Firms with HQ in the SBC:

$$
C_{i, j, z}^{h}=(K \cdot \rho)^{\eta} \cdot\left(H_{i, i, i}^{h}\right)^{\eta}\left(Q_{i}^{m+h}\right)^{1-\eta} x_{i, j, z}^{h} ;
$$

\footnotetext{
${ }^{14}$ See Duranton and Puga (2005) Lemma 1 and 2.

${ }^{15}$ Remember that each individual inelastically supply one unit of labour but has to commute to the city CBD to effectively work in a firm. This implies that a fraction $\tau$ of the total city work supply get lost and $\sum_{h=0}^{2 m} l_{i}^{h}=$ $L_{i}\left(1-\tau L_{i}\right)$.

${ }^{16} \mathrm{Or}$ the cost advantages stemming from co-location of inputs producers belonging to the same sector.

${ }^{17}$ We identify the location of a final good firm with the location of its headquarter.

${ }^{18}$ First subscript indicates the city where firm's HQ is located, the second the city where PP is located and the third indicates the PBC.
} 
where $\rho>1$ and $K>1$ are the extra-headquarter requirements respectively associated with the transmission of headquarter services to a PP located in a different city (the managing costs) and with the transmission of business services from business services suppliers to headquarters located away from the PBC (the transaction costs). A multi-location firm is thus supposed to face both these iceberg costs and to have its headquarter sub-cost function multiplied by a factor $\rho \cdot K>K, \rho$.

\section{City formation}

In section 2 I have defined the consumption expenditure income of a consumer/worker in the spatial economy (see (6)) and this has been shown to be function of both spatial and market features. Since individuals face no spatial relocation costs and no costs in shifting from an occupation to another, they will move to the city which grants them the higher wage and the lower urban costs. A spatial equilibrium is then reached when a consumer has no incentive to move from a city to another; from the model's assumptions on consumers preferences, this means that she/him will get the same consumption expenditure income everywhere, given the location choices of other consumers and the organisational and location choices of firms. In the model, attraction and repulsion forces - which are the basis of cities' existence - are thus exclusively affecting consumers/workers: the agglomeration economies, in fact, stem from the gathering of an occupation-specific workforce, while the countervailing (dispersion) force is represented by the commuting costs. ${ }^{19}$

In the present model, a "land development companies" mechanism leads to the formation of cities and, therefore, determines equilibrium city sizes. ${ }^{20}$ The prefectly competitive land development companies (henceforth LD) seek to maximise total land rent in the city by choosing a population target and an occupation specific monetary transfer scheme. The latter is defined as the $(2 m+1)$-dimensional vector $T_{i}=\left\{T_{i}^{0}, T_{i}^{1}, \ldots, T_{i}^{h}, \ldots T_{i}^{m}, \ldots, T_{i}^{m+h}, \ldots, T_{i}^{2 m}\right\}$ whose components represent the amount of money which a worker earn from the LD when moving to the city $i$. This amounts to saying that each LD maximises the following objective function:

$$
\max _{\left\{L_{i}^{h}, T_{i}^{h}\right\}} \Pi_{i}, \quad \Pi_{i}=R_{i}-\sum_{h=0}^{2 m} L_{i}^{h} T_{i}^{h}
$$

subject to workers in each active occupation in the city obtaining the highest consumption income available elsewhere, $\bar{e}$ :

$$
L_{i}^{h} e_{i}^{h}=L_{i}^{h} \bar{e}, \quad L_{i}^{h} \geq 0
$$

and subject also to firms adopting each of the possible configurations breaking even. ${ }^{21}$ Moreover,

\footnotetext{
${ }^{19}$ No final goods' price index effect, which is the one acting as dispersion force in the standard framework of the New Economic Geography, is modelled here, since final good is homogenous and freely traded across locations.

${ }^{20}$ With regards to this issue see Henderson and Becker (2000). In the literature, two main approaches to city formation and size may be distinguished: self-organisation and perfectly competitive land development companies. The main advantage of the latter setting lies on the fact that it allows to get rid of inefficient spatial equilibria arising under coordination failure between agents.

${ }^{21}$ This implies that each firm's establishment, whether it is a production plant a headquarter of a multi-location firm or an integrated firm, has to break even, wherever it is located. See Appendix A for the definition of the necessary conditions associated to all the possible cases.
} 
following Duranton and Puga (2005), developer's programme may be rewritten as:

$$
\max _{l_{i}^{h}} \Pi_{i}, \quad \Pi_{i}=\sum_{h=0}^{2 m} w_{i}^{h} l_{i}^{h}-L_{i} \bar{e}
$$

subject to (A.1-A.6), $l_{i}^{h} \geq 0$ and $\sum_{h=0}^{2 m} l_{i}^{h}=L_{i}\left(1-\tau L_{i}\right)$. From (18)

If the break even conditions for final good firms hold, one can state what follows.

Lemma 1 [Multi-location HQs and PPs separation.] In equilibrium, the stand alone headquarters and the stand-alone production plants belonging to any type of multi-location firms (i.e. those with HQs in the PBC and those with HQs outside the PBC) do not coexist in the same city.

Proof. The HQs of a multi-location firm which are located outside the PBC cannot co-exist with the PPs of a different multi-location firm. In fact, this would imply that an integrated firm located in the same city would have the chance to get HQ's and PP's services at the lowest cost though saving the communication cost associated to the managing at distance. As a consequence, this firm, would make positive profits equal to $P^{h}-\left(H_{i, i, i}^{h}\right)^{\eta}\left(Q_{i}^{m+h}\right)^{1-\eta}=\left(1-1 /(K \rho)^{\eta}\right) P^{h}>0$, which contradicts (A.1-A.2).

While the latter Lemma rules out the city types encompassing stand-alone HQs and standalone PPs (i.e. if a city is supposed to host both facilities, then these must belong to the same integrated final good firm), from the definition of the maximisation problem in $(18)^{22}$, we can exclude the co-presence of integrated firms and HQs or PPs belonging to multi-location firms. That is, whether in the PBC or not, in equilibrium, integrated firms cannot co-exist with either HQs or PPs of multi-location firms belonging to the same sector. This leads to the definition of the the city-types which are feasible in equilibrium:

(a) HQs (belonging to multi-location firms) and business service suppliers of both types;

(b) HQs of multi-location firms;

(c) PPs (belonging to multi-location firms) and intermediate suppliers;

(d) integrated firms, business service suppliers of both types and intermediates suppliers;

(e) integrated firms and intermediates suppliers;

(f) ABS suppliers.

Note that, from now on, this labeling will also characterise city-type specific variables (as an example, $L_{a}$ will be unsed to indicate th total equilibrium population of a city hosting HQs and business service suppliers). I may now determine equilibrium city sizes:

\footnotetext{
${ }^{22}$ See also (B.14) for a different formulation of the maximisation problem. From this it also results as straightforward the result for which each city end up as sectorally specialised in equilibrium, regardless of the degree of functional specialisation associated to each of the feasible urban configurations.
} 
Lemma 2 [Equilibrium city sizes] The spatial equilibrium city-sizes are

$$
\begin{gathered}
L_{a}=\frac{\sigma}{\tau(1+2 \sigma)}, \quad L_{c}=\frac{\epsilon}{\tau(1+2 \epsilon)}, \quad L_{d}=\frac{\gamma}{\tau(1+2 \gamma)}, \\
L_{b}=\frac{1+\mu}{\tau(1+2 \mu)}, \quad L_{e}=\frac{\epsilon(1-\eta)}{\tau[1+2 \epsilon(1-\eta)]}, \quad L_{f}=\frac{\sigma}{\tau(1-\mu+2 \sigma)} .
\end{gathered}
$$

Proof. See C.

Once defined city types and the relative sizes I can define the equilibrium configurations as, alternatively, encompassing:

1. only type (d)-cities (firms face the cost function of (14));

2. type (e) and (f) cities (firms face the cost function of (15));

3. type (a) and (c) cities (firms face the cost function of (16));

4. type (e), (f) and (c) cities (firms face the cost function of (17)).

Figure 1 represents the four equilibrium configurations. Dotted lines indicate integrated firms, while arrows indicates additional costs $\rho$ and $K$ faced by headquarters under different spatial equilibria.
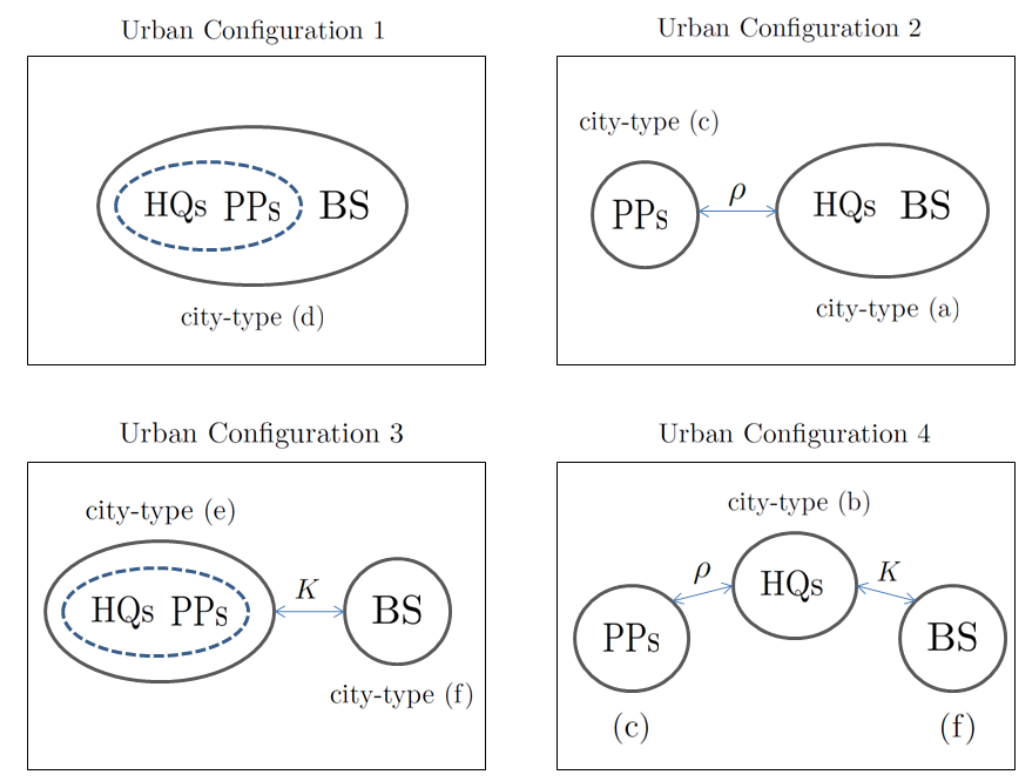

Figure 1: Spatial economy's feasible equilibria 


\section{Urban configurations and the interplay between communica- tion costs}

\subsection{Communication costs' thresholds}

The following proposition identifies the conditions, expressed in terms of the level of the two communication costs, under which the four configurations listed in the latter section will result as equilibrium outcomes.

Proposition 1 [Equilibrium firm organisation and urban structure] For $\rho>\hat{\rho}$, where

$$
\hat{\rho}=\left[\frac{(1+2 \gamma)^{1+2 \gamma} \sigma^{\eta \sigma} \epsilon^{(1-\eta) \epsilon}}{\gamma^{\gamma}\left[\eta^{\sigma}(1+2 \sigma)^{1+2 \sigma}\right]^{\eta}\left[(1-\eta)^{\epsilon}(1+2 \epsilon)^{1+2 \epsilon}\right]^{1-\eta}}\right]^{1 / \eta}
$$

then all firms adopt the fully integrated organisational form of (14), and all cities specialise by sector, hosting headquarters, production plants, business services and intermediates suppliers. If instead $\rho<\hat{\rho}$, then all firms adopt the partial multi-location organisational form of (16) keeping headquarters in the business service center, with a share

$$
\frac{\eta \epsilon(1+2 \sigma)}{\eta \epsilon(1+2 \sigma)+(1-\eta)(1+2 \epsilon) \sigma}
$$

of cities hosting headquarters and business services suppliers, and the rest of cities hosting production plants plus intermediate suppliers.

For $K>\hat{K}$, where

$$
\hat{K}=\left[\frac{(1+2 \gamma)^{1+2 \gamma}[\epsilon(1-\eta)]^{\epsilon(1-\eta)}[1-(1-\mu) \eta]^{1-\eta(1-\mu)}(1-\mu)^{\eta(1-\mu)} \sigma^{\eta \sigma}}{(1+2 \sigma-\mu)^{\eta(1+2 \sigma-\mu)}[1+2 \epsilon(1-\eta)]^{1+2 \epsilon(1-\eta)-\eta(1-\mu)} \gamma^{\gamma} \mu^{\mu \eta} \eta^{\eta \sigma}}\right]^{1 / \eta}
$$

then all firms adopt the fully integrated organisational form of (14) and all cities specialise by sector, hosting headquarters, production plants, business services and intermediates suppliers. If instead $K<\hat{K}$, then all firms adopt the partial multi-location organisational form of (15) (keeping headquarters together with production plants while facing an additional cost to get business services from outside the city) with a share

$$
\frac{\epsilon \eta(1-\mu)(1+2 \sigma-\mu)}{\epsilon \eta(1-\mu)^{2}+\sigma+2 \epsilon \sigma(1-\mu \eta)}
$$

of $P B C$, and the rest of cities hosting headquarters, production plants and intermediate suppliers. For $\rho<\hat{\rho}$ and $K<\hat{K}$ all firms necessarily adopt the multi-location organisational form of of (17).

For $K<\hat{K}$ and $\rho>\bar{\rho}$, where

$$
\bar{\rho}=\left[\frac{[1+2 \epsilon(1-\eta)]^{1+2 \epsilon(1-\eta)-\eta(1-\mu)}[1-(1-\mu) \eta]^{\eta(1-\mu)-1}\left(\mu^{2} \eta\right)^{\mu \eta}}{(1-\eta)^{2 \epsilon(1-\eta)+\eta \mu}(1+2 \epsilon)^{(1+2 \epsilon)(1-\eta)}[(1+\epsilon)(1+2 \mu)]^{\mu \eta}}\right]^{1 / \eta}
$$

then all firms adopt the partial multi-location organisational form of (15). If instead $\rho<\bar{\rho}$, then all firms shift from the organisational form of (15) to that of of (17) with a share

$$
\frac{\epsilon(1-\mu)(1+\mu) \eta(1+2 \sigma-\mu)}{\epsilon(1-\mu)^{2}(1+\mu) \eta+\epsilon[2+\mu(2-\eta)]+(1+\mu)(1-\eta) \sigma}
$$


of PBC hosting only business services suppliers, and a share

$$
\frac{\epsilon \mu \eta \sigma(1+2 \mu)}{\epsilon(1-\mu)^{2}(1+\mu) \eta+\{\epsilon[2+\mu(2-\eta)]+(1+\mu)(1-\eta)\} \sigma}
$$

of cities hosting only headquarters. If $\rho<\hat{\rho}$ and $K>\bar{K}$, where

$$
\bar{K}=\left[\frac{(1-\mu)^{\eta(1-\mu)} \mu^{\mu \eta}(1+2 \sigma)^{\eta(1+2 \sigma)}}{(1-\mu+2 \sigma)^{\eta(1-\mu+2 \sigma)}(1+2 \mu)^{\eta \mu}}\right]^{1 / \eta}
$$

then all firms adopt the partial multi-location organisational form of (16). If instead $K<\bar{K}$, then all firms shift from the organisational form of (16) to that of (17).

\section{Proof. See D.}

\subsection{Discussion}

In the latter subsection I have presented the main result of the paper, which consists in the identification of the communication costs critical levels (19-22). According to the model hypotesis, held constant the magnitude of the localisation economies, the emergence of one of the four feasible types of system of cities is determined by the level of the communication costs faced by firms. The way communication costs affect firms decisions depends on the starting urban configuration, that is, co-location of headquarters and ABS is affected by the level of the additional cost of buying ABS from distance, but also by the level of the managing cost. The reverse relation is also proven to hold: even firms' integration is affected by both communication costs. Thus headquarters' location with respect to the ABS affects the organisational decision of firms. This amount to saying that:

$$
\rho^{*} \equiv\left\{\begin{array}{ll}
\hat{\rho} & \forall K>\hat{K} \\
\bar{\rho} & \forall K<\hat{K}
\end{array} \quad ; \quad K^{*} \equiv\left\{\begin{array}{ll}
\hat{K} & \forall \rho>\hat{\rho} \\
\bar{K} & \forall \rho<\hat{\rho}
\end{array} .\right.\right.
$$

Where $\rho^{*}$ and $K^{*}$ represents the relevant thresholds. Moreover, note that since we have not so far imposed any restriction on the parameter values, nothing in the model prevents each threshold to assume values below unity. This would obviously imply their non-existence. In fact, in the presence of a threshold below unity, the correspondent communication cost should turn negative in order to deliver any spatial separation. Furthermore, the relative position of each of the four thresholds is not a priori defined, so that, in principle, $\bar{K} \lesseqgtr \hat{K}$ and $\bar{\rho} \lesseqgtr \hat{\rho}$. Figure 2a illustrates the four feasible urban configurations (with correspondent city-types in parenthesis) as functions of the levels of communication costs $\rho$ and $K$, in the space definded by $\rho>1$ and $K>1$. 


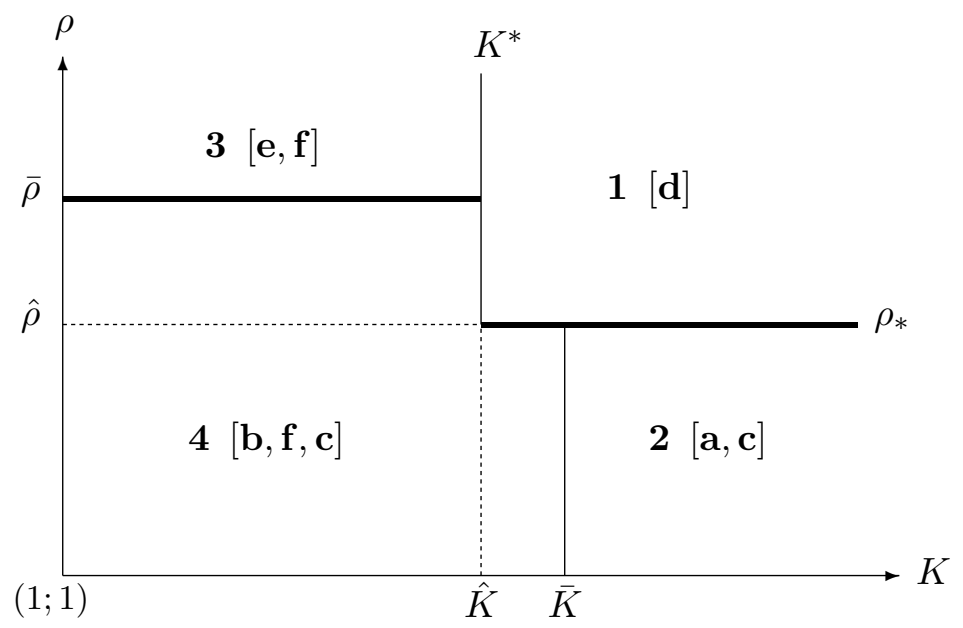

Figure 2a: Feasible spatial configurations and relevant thresholds

According to what stated so far, if the ABS communication cost $K$ falls below the threshold $\hat{K}$, while the managing cost $\rho$ stays above the threshold $\bar{\rho}$, the economy shifts from the integrated configuration 1 to the configuration 3 , where firms adopt an integrated organisational form but locate in a different city with respect to the ABS providers. Once this equilibrium is reached, no further decrease of $K$ can deliver the urban configuration of maximum functional specialisation 4: firms' separation into headquarters and production plants is worthwhile for the economy only if $\rho$ falls below $\bar{\rho}$.

On the other side, only if $K$ stays above $\hat{K}$ and $\rho$ falls below $\hat{\rho}$ the economy shifts from the integrated configuration 1 to the configuration 2 where firms split into PPs and HQs but keep the latters in the PBC. Starting from this partially specialised configuration, no further decrease of $\rho$ can lead to maximum functional specialisation 4: only a decrease of $K$ under the threshold $\bar{K}$ pushes headquarters away from the PBC. Thus, in order for maximum functional specialisation to be a feasible spatial equilibrium, the conditions $K<\bar{K}$ and $\rho<\bar{\rho}$ have to be jointly met.

However, figure $2 \mathrm{a}$ is not the unique representation of equilibrium configurations in the $\rho-K$ parameter space. From Proposition 1, in fact, each threshold is a function of the parameters $\sigma$, $\epsilon, \gamma, \mu$ and $\eta$. Thus, according to their values, a situation in which $\hat{K}>\bar{K}$ and/or $\hat{\rho}>\bar{\rho}$ may arise.

In order to provide a numerical example, we may assume the following: $\theta=0.2, \epsilon=0.05$, $\mu=0.6$ and $\eta=0.2$. This amount to saying that a $1 \%$ increase in employment in a city hosting ABS raises local productivity by $1.08 \%$ (note that $\sigma=\theta(1-\mu)=0.08$ ) while a $1 \%$ increase in employment in a city hosting PPs and intermediates suppliers raises local productivity by $1.05 \%$. Moreover, the share of the total firm's cost represented by headquarters' services is quite low $(20 \%)$ and the workforce directly occupied in the headquarter account for the larger part of the corrsepondent sub-cost function $(60 \%)^{23}$. In correspondence of these parameter values, we find that $\hat{\rho}=1.17, \hat{K}=1.15, \bar{\rho}=0.22$ and $\bar{K}=0.51$.

\footnotetext{
${ }^{23}$ In the following I always assume that $\mu \geq 0.6$ which is consistent with the empirical results provided by Aarland et al. (2007).
} 
This results depict a spatial economy in which urban configuration 4 is not sustainable for any level of $\rho$ and $K$ (figure $2 \mathrm{~b}$ ). ${ }^{24}$

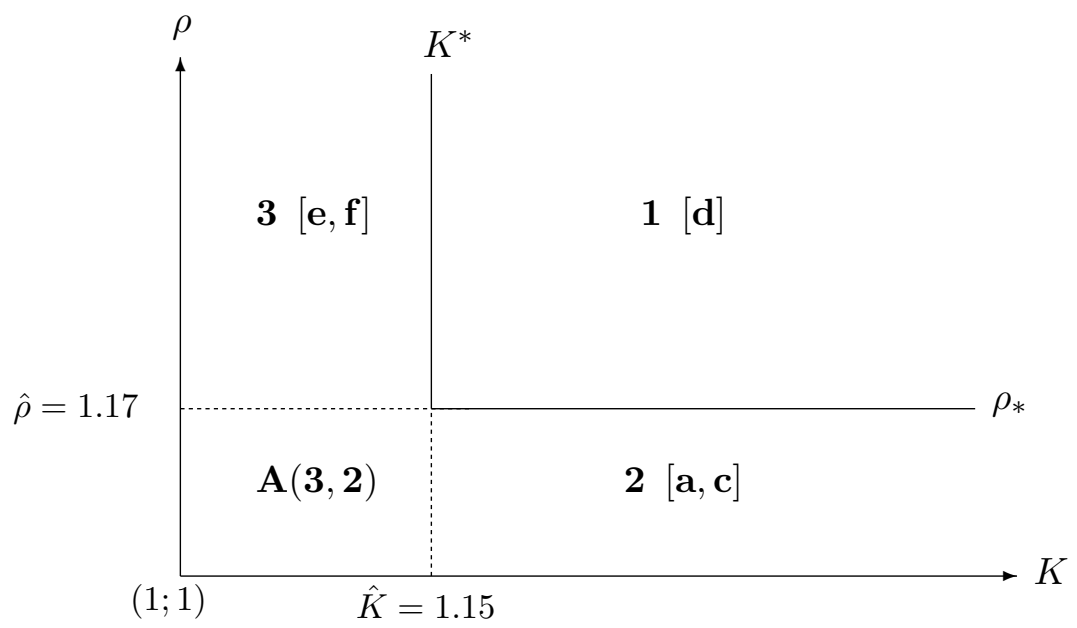

Figure 2b: Feasible spatial configurations and relevant thresholds for $\theta=0.2, \epsilon=0.05, \mu=0.6$ and $\eta=0.2$

Note that the parameter space represented by area $A$ in figure $2 \mathrm{~b}$ may, alternatively, deliver configuration 3 or 2 , depending on the starting levels of $\rho$ and $K$. This implies that once reached configuration 3 or 2 from 1 , no further decrease of $\rho$ or $K$, respectively below $\hat{\rho}$ and $\hat{K}$, may lead to a different spatial equilibrium. This latter result, arises for $\bar{\rho}<1<\hat{\rho}$ or $\bar{K}<1<\hat{K}$ and entails a sort of spatial lock-in effect. To this regard, the complexity of (19), (20), (21) and (22) do not allow to find handy expressions for the ranges of $\mu, \eta, \epsilon$ and $\sigma$ which ensure that the latter conditions hold. It is nevertheless possible to proceed numerically. This delivers the following results:

(i) $\hat{\rho} \geq 1$ for all admissible parameter values;

(ii) $\bar{\rho}>1$ for $\eta \geq 0.8$;

(iii) if $\bar{\rho}>1$ holds, then $\bar{\rho}>\hat{\rho}$ also holds;

(iv) $\bar{K} \leq 1$ for all admissible parameter values;

(v) $\hat{K}>1$ for $\sigma>0.01$.

I start by analysing the former three points which concern the managing cost $\rho$. With regards to this, in Figure 3, $\bar{\rho}$ and $\hat{\rho}$ are plotted as functions of $\eta$.

\footnotetext{
${ }^{24}$ In the limit case in which all the thresholds are below unity, neither configurations 2 and 3 are feasible and the spatial economy is necessarily characterised by cities of the integrated type $d$ : sectoral specialisation and no functional specialisation.
} 


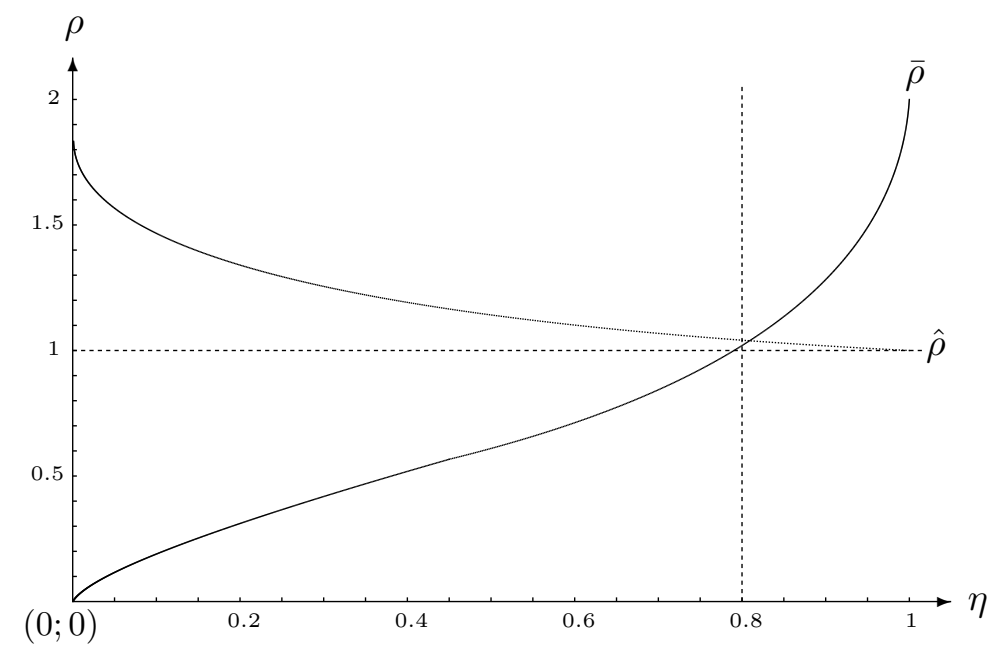

Figure 3: Determinants of $\rho$-thresholds given $\epsilon=0.05$ and $\mu=0.6$

Held constant the values of the remaining parameters $-\bar{\rho}>1$ holds for all $\eta>0.8$, while $\hat{\rho}>1$ holds in the whole admissible parameter range. The conclusion that we can draw from this result is that configuration 4 is feasible if and only if $\eta>0.8$. Moreover, (point (ii)) for sufficiently high values of $\eta$, a substitution effect between $\rho$ and $K$ exists in shifting from 1 to 4 via 3. This amounts to saying that the lower $\rho$, the more likely is for HQs to locate away from PBC.

In fact, if we assume that $\eta=0.8$, then $\hat{\rho}=1.04$ and $\bar{\rho}=1.08$ : the shift from configuration 1 to 2 then becomes feasible if the additional cost of managing production from distance falls below $4 \%$ of the managing cost for an integrated firm, while an $8 \%$ threshold is fixed with respect to the shift from configuration 3 to 4 . As $\eta$ rises this substitution effect rises, together with the spread between $\bar{\rho}$ and $\hat{\rho}$. In order to better understand why this happens, we may focus on the determinants of both thresholds, starting from the case of $\hat{\rho}$. According to the simulation results, and limiting the analysis to the relevant case $\eta \geq 0.8$, we have that:

$$
\frac{\partial \hat{\rho}}{\partial \sigma}>0, \forall \sigma \in\left[0, \frac{\epsilon}{2}\right] ; \frac{\partial \hat{\rho}}{\partial \eta}<0 ; \frac{\partial \hat{\rho}}{\partial \epsilon}>0 .
$$

Note that from (23), the intuitive result for which the more localisation economies in the ABS sector, the more the multi-location firm's organisational form is supposed to become worthwhile, holds as long as $\sigma<\frac{\epsilon}{2}$. In order to understand why the magnitude of these localisation economies have to keep low relative to those associated to the production of intermediates we may consider, first of all, that we are restricting the analysis to a portion of the parameter space in which $\eta$ is relatively high. In this specific case, the benefits accruing to firms from the geographical separation between HQs and PPs are very low $\left(\frac{\partial \hat{\rho}}{\partial \eta}<0\right)$, since local productivities are not significantly hindered by the mixing between the different workforces which arises in case of spatial integration. The latter consideration is confirmed by the sign of the following cross derivatives with respect to $\eta$ :

$$
\frac{\partial \hat{\rho}}{\partial \sigma \partial \eta}<0 ; \frac{\partial \hat{\rho}}{\partial \epsilon \partial \eta}<0
$$


These imply that a rising $\eta$ lowers the effect exerted by the localisation economies on the firm's organisational decision. Secondly, as $\sigma$ rises, the congestion associated to the a-type cities rises more than proportionately than that associated to the d-type ones.

For what concerns $\bar{\rho}$ instead, the sign of the derivatives can be determined on the whole parameter range. Accordingly, we have that:

$$
\frac{\partial \bar{\rho}}{\partial \sigma}=0, \frac{\partial \bar{\rho}}{\partial \eta}>0 \forall \mu \in[0.15,1] ; \frac{\partial \bar{\rho}}{\partial \mu}>0 \forall \eta \in[0.8,1] ; \frac{\partial \bar{\rho}}{\partial \epsilon}<0 \forall \eta \in[0.8,1] .
$$

Note that the derivative with respect to the parameter $\sigma$ is null. This threshold is in fact associated to the shift from configuration 3 to 4 , which entails spatial separation between HQ and PP, while ABS are already agglomerated in the same city (f-type). Firms has thus just exploited the localisation economies represented by $\sigma$, that is, they have benefited from the increase in productivity which stems from locating HQs away from business services. Figure 4 illustrates the results in (24).

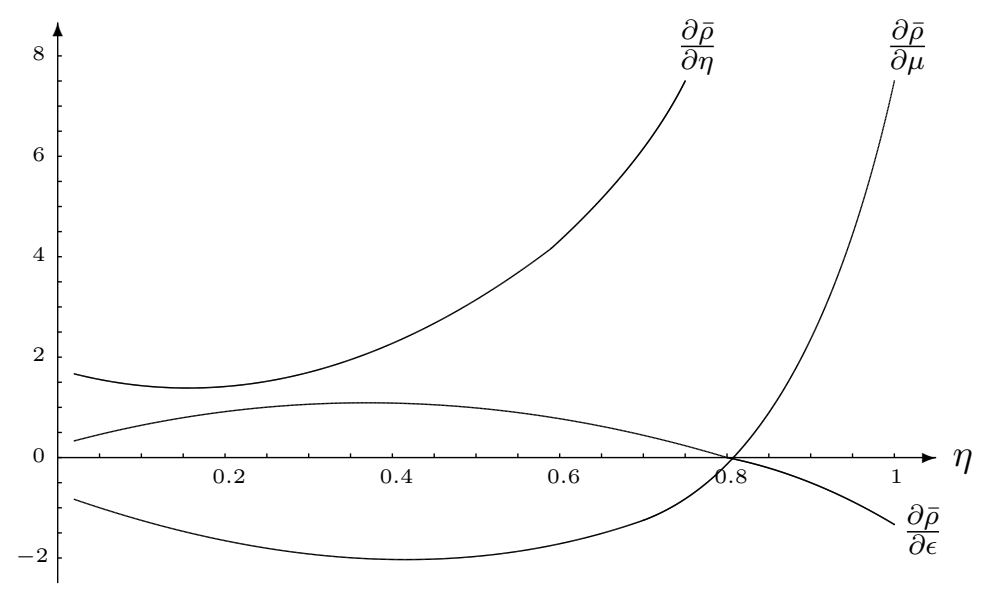

Figure 4: Determinants of $\bar{\rho}$ given $\epsilon=0.05$ and $\mu=0.6$

Thus, as far as $\eta<0.8$, this threshold is decreasing in $\mu$ and increasing in $\epsilon$ while the opposite is true for $\eta>0.8$. To understand why this happens, consider that Lemma 2 also implies: ${ }^{25}$

$$
L_{b}>L_{f}>L_{a}>L_{d}>L_{c}>L_{e}
$$

so that shifting from configuration 3 to 4 is not only associated to a lower price for intermediates ${ }^{26}$ but also to a higher level of congestion, since $L_{b}+L_{c}>L_{e}$ always holds. A higher number of workers directly occupied in the HQs thus entails an increase in the size of b-type cities. ${ }^{27}$ For $\eta<0.8$, this is sufficient to explain why a higher $\mu$ is supposed to negatively affect the threshold

\footnotetext{
${ }^{25}$ In particular, for any value of $\mu, \tau$ and for $\sigma>\epsilon, L_{b}>L_{f}>L_{a}>L_{d}>L_{c}>L_{e}$ holds, while for $\sigma<\epsilon$ and for $1-10 \sigma<\mu<1, L_{b}>L_{f}>L_{c}>L_{d}>L_{a}>L_{e}$ holds.

${ }^{26}$ This is due to the fact that in configuration 4 the co-existence of HQs and PPs is avoided and the model only encompasses localisation economies for intermediates producers.

${ }^{27}$ Note that $\sigma$ is an inverse function of $\mu$, so that a rise in $\mu$ is necessarily associated to a lower degree of localisation economies in the ABS sector. Notwithstanding this, we have already explained that changes in $\sigma$ do not affect the feasibility of configuration 4 starting from 3 .
} 
value $\bar{\rho}$, while the intuition for the sign of $\frac{\partial \bar{\rho}}{\partial \epsilon}$ is straightforward: a higher degree of localisation economies, favours firm's spatial separation.

However, once $\eta$ is sufficiently high, $\mu$ becomes a positive determinant of the level of $\bar{\rho}$. This happens nothwithstanding the fact that a higher $\mu$ is still associated with larger b-type cities. This loss in terms of congestion associated to the shifting to configuration 4 , in fact, is now more than compensated by a gain in terms of higher localisation economies for the production of intermediates. That is, the change in the sign of $\frac{\partial \bar{\rho}}{\partial \mu}$ is due to the fact that a higher $\eta$ has a negative effect on the degree of localisation economies in configuration 3 , since it jointly reduces the size of e-type cities and increases their share of headquarters workforce. As a consequence, a rise of $\mu$, as well as a decrese of $\epsilon$, exacerbates this negative effects thereby favouring the urban configuration which encompasses maximum functional specialisation.

To sum up, if HQ's sub cost function represents a sufficiently large share of total cost function and, moreover, if the labor force directly employed in HQs is a sufficiently high share of the headquarters' sub-cost function, the potential gains for firms and LDs which stem from shifting from configuration 3 to 4 are greater than the losses, and the threshold is greater than unity. In the opposite case, the shift from 3 to 4 would not free enough resources with respect to the additional congestion it would induce, and the threshold would thus be likely to disappear. The spread between the two thresholds $(\bar{\rho}-\hat{\rho})$ only affects the extent of the $(\rho, K)$ range in which configuration 4 is feasible and represents a good measure of the degree of substitutability between the two types of communication costs. This spread is supposed to be strictly increasing in the magnitude of localisation economies, that is, in $\sigma$ and $\epsilon$. This is due to the fact that while $\hat{\rho}$ is stricly decreasing with respect to the latters, $\bar{\rho}$ is constant over $\sigma$ and, moreover, $\left|\frac{\partial \bar{\rho}}{\partial \epsilon}\right|<\left|\frac{\partial \hat{\rho}}{\partial \epsilon}\right|$ for all the admissible parameter values.

We may now move to point (iv) and (v), which concern the remaining thresholds $\hat{K}$ and $\bar{K}$. Point (iv) implies that the only way an economy may reach configuration 4 is through 3 , provided that $\bar{\rho} \geq 1$. In different terms, multi-location firms won't ever find it profitable to move HQs to a SBC. This result is particularly significant: as far as we accept the hypothesis that change in the spatial organisation of firms are predominantly led by the exogenous dynamics of communication costs, it implies that some urban systems may result stuck in a partially specialised spatial equilibrium as long as the remaining determinants, which attain to the degree of substitutability between varieties and to the cost functions of final good firms, do not change. Furthermore, point (v) allows us to conclude that, unless the localisation economies associated with ABS are very low, a transition from the integrated configuration 1 to 2 is always feasible. The level of $\hat{K}$ is obviously strictly increasing in $\sigma$ and $\eta$.

Finally, in order to further characterise single equilibrium configurations, in the following table I present the shares of each of the city type, given the benchmark parameter values.

By comparing configuration 3 with 4 we can clearly notice that, fixed the number of cities specialised in business services, no sensible change occurs in the number of cities specialised in the production of intermediates: from $97 \%$ to $96 \%$. The remaining $1 \%$ is represented by headquarters' urban centers. Configuration 2 is instead characterised by a lower degree of spatial agglomeration, due to the equilibrium dimension of a-type cities, which is significantly lower than that of f-type and b-type ones. 


\begin{tabular}{cccc}
\cline { 2 - 4 } & \multicolumn{3}{c}{ Configuration } \\
\cline { 2 - 4 } & 2 & 3 & 4 \\
\hline$L_{a}$ & 0.16 & - & - \\
$L_{b}$ & - & - & 0.01 \\
$L_{c}$ & 0.84 & - & 0.96 \\
$L_{e}$ & - & 0.97 & - \\
$L_{f}$ & - & 0.03 & 0.03 \\
\hline
\end{tabular}

Table 1: Shares of total cities for city-type and equilibrium urban configuration

\section{Concluding remarks}

The model presented in this paper extends the work of Duranton and Puga (2005) according to which the functional specialisation of urban systems is the outcome of coordinated spatial organisation decisions of firms producing final goods. In the original model, firms could only decide whether remaining integrated or splitting up into headquarters and production plants, where the latter option necessarily implied locating the two facilities in different cities. According to this framework, the decision was in fact predominantly lead by the level of the communication cost between the two facilities, i.e. the cost of managing production plants at distance. The novel part of my model consists in the introduction of an additional dimension to the firm's spatial problem. Firms may thus decide whether locating their headquarters in the business service center with business sector or in a different city where they can release some congestion costs at the expense of an additional communication cost. The latter must be intended as a transaction cost or, equivalently, as a higher price for advanced business services. This enriched framework allows me to investigate the effects on the urban structure of the interplay between the dynamics of both types of communication costs.

I find that the spatial equilibrium characterised by maximum functional specialisation and by the emergence of secondary business centers is not feasible for a large set of parameter values. In most of the cases, in fact, the economy is likely to shift from an integrated spatial organisation where all the cities host all the functions - to a partially specialised one which may accommodate (i) cities hosting integrated firms and cities hosting advanced business services providers, (ii) cities hosting production plants and cities hosting headquarters and advanced business services providers.

Moreover, numerical simulations have shown that maximum functional specialisation turns out to be feasible only for those economies which are characterised by the presence of final good firms with a relatively small share of their cost function represented by production plants. This suggests, as expected, that only service oriented economies are worth of reaching the highest level of functional specialisation.

Another remarkable result is that, even if feasible, the maximum functional specialisation may emerge only provided that economy is already partially specialised, that is, already accomodates primary business centers. This happens if the communication costs between the firm and the advanced business services providers are sufficiently low, while firms have not enough incentives to separate managers from production plants. On the contrary, the alternative partially specialised spatial equilibrium encompassing for small manufacturing cities and cities hosting business service providers and headquarters is a stable one, as well as once reached, no further 
decrease in communication costs can make the economy shift to a higher degree of functional specialisation. This could be the case of an economy characterised by a significant presence of multinational firms with managing separated from production and headquarters located in global cities. In this case, the model do not predict sufficient incentives for these firms to proceed in further spatial diversification by moving headquarters away from that business centers.

Finally, when perfect functional specialisation is feasible, the model also predicts a non-linear substitution effect between communication costs: when the extra cost associated to buying advanced business services at distance is sufficiently low, the spatial separation between firms' headquarters and production plants is more likely to occur. The extent of localisation economies for business services and intermediate producers only affects the magnitude of the degree of substitutability between communication costs.

\section{References}

Aarland, K., Davis, J., Henderson, J. V., Ono, Y., 2007. Spatial Organization of Firms: The Decision to Split Production and Administration. The Rand Journal of Economics 38 (2), 480-494. 2, 4, 15

Abdel-Rahman, H., Fujita, M., 1990. Product Variety, Marshallian Externalities, and City Sizes. Journal of Regional Science 30 (2), 165-183. 7

Audretsch, D., Falck, O., Heblich, S., 1990. Who's got the aces up his sleeve? Functional specialization of cities and entrepreneurship. The Annals of Regional Science 46 (3), 621-636. 5

Cavailhés, J., Gaigné, C., Tabuchi, T. and Thisse, J.-F., 2007. Trade and the structure of cities. Journal of Urban Economics 62 (3), 383-404. 4

Davis, J. C., Henderson, J. V., 2008. The agglomeration of headquarters. Regional Science and Urban Economics 38 (5), 445-460. 2

Defever, F., 2006. Functional fragmentation and the location of multinational firms in the enlarged Europe. Regional Science and Urban Economics 36 (5), 658-677. 2

Defever, F., 2012. The spatial organization of multinational firms. Canadian Journal of Economics/Revue canadienne d'économique 45 (2), 672-697. 2

Diacon, T., Klier, T., 2003. Where the headquarters are - evidence from large public companies 1990-2000. Federal Reserve Bank of Chicago, WP-03-35. 5

Duranton, G., Puga, D., 2001. Nursery Cities: Urban Diversity, Process Innovation, and the Life Cycle of Products. American Economic Review 91 (5), 1454-1477. 2

Duranton, G., Puga, D., 2004. Micro-foundations of urban agglomeration economies. Handbook of regional and urban economics 4, 2063-2117. 26

Duranton, G., Puga, D., 2005. From sectoral to functional urban specialisation. Journal of Urban Economics 57 (2), 343-370. 3, 4, 9, 11, 20, 26 
Ethier, W. J., 1982. National and International Returns to Scale in the Modern Theory of International Trade. American Economic Review 72 (3), 389-405. 7

Fujita, M., Krugman, P., Mori, T., 1999. On the evolution of hierarchical urban systems. European Economic Review 43 (2), 209-251. 6

Fujita, M., Mori, T., 1997. Structural stability and evolution of urban systems. Regional Science and Urban Economics 27 (4), 399-442. 6

Fujita, M., Thisse, J.-F., 2006. Globalization And The Evolution Of The Supply Chain: Who Gains And Who Loses?. International Economic Review 47 (3), 811-836. 4

Henderson, J. V., Ono, Y., 2008. Where do manufacturing firms locate their headquarters?. Journal of Urban Economic 63 (2), 431-450. 5

Henderson, J. V., Becker, R., 2000. Political Economy of City Sizes and Formation. Journal of Urban Economic 48 (3), 453-484. 10

Ioannides, Y. M., Overman, H. G., Rossi-Hansberg, E., 2008. The effect of information and communication technologies on urban structure. Economic Policy 23 (54), 203-242. 4

Jacobs, W., Koster, H. R. A., van Oort, F., 2013. Co-agglomeration of knowledge-intensive business services and multinational enterprises. Journal of Economic Geography, 1-33. 2

Lovely, M. E., Rosenthal, S., Sharma, S., 2005. Information, agglomeration, and the headquarters of U.S. exporters. Regional Science and Urban Economics 35 (2), 167-191. 2

Ono, Y., 2003. Outsourcing business services and the role of central administrative offices. Journal of Urban Economics 53 (3), 377-395. 5

Ono, Y., 2007. Market thickness and outsourcing services. Regional Science and Urban Economics 37 (2), 220-238. 5

Rossi-Hansberg, E., Wright, M. L., 2007. Urban Structure and Growth. Review of Economic Studies 74 (2), 597-624. 4

Rossi-Hansberg, E., Sartre, P. D., Owens III, R., 2009. Firm Fragmentation and Urban Patterns. International Economic Review 50 (1), 143-186. 4

Strauss-Kahn, V., Vives, X., 2009. Why and Where do Headquarters Move?. Regional Science and Urban Economics 39 (2), 168-186. 2

Wen-Chi, L., 2012. Inshoring: the Geographic Fragmentation of Production and Inequality. Journal of Urban Economics 72 (1), 1-16. 4 


\section{A Break even conditions}

(i) HQs and PPs of a firm integrated in the PBC;

$$
\begin{aligned}
& x_{i, i, i}^{h}\left[P^{h}-\left(H_{i, i, i}^{h}\right)^{\eta}\left(Q_{i}^{m+h}\right)^{1-\eta}\right]=0, \quad P^{h}-\left(H_{i, i, i}^{h}\right)^{\eta}\left(Q_{i}^{m+h}\right)^{1-\eta} \leq 0, \\
& x_{i, i, i}^{h} \geq 0
\end{aligned}
$$

(ii) HQs and PPs of a firm integrated outside the PBC (establishment integrated in a SBD);

$$
\begin{aligned}
& \left(\int_{z \neq i} x_{i, i, z}^{h} d z\right)\left[P^{h}-\left(K \cdot H_{i, i, i}^{h}\right)^{\eta}\left(Q_{i}^{m+h}\right)^{1-\eta}\right]=0, \\
& P^{h}-\left(K \cdot H_{i, i, i}^{h}\right)^{\eta}\left(Q_{i}^{m+h}\right)^{1-\eta} \leq 0, \quad \int_{z \neq i} x_{i, i, z}^{h} d z \geq 0
\end{aligned}
$$

(iii) HQs of a multi-location firm, located in the PBC;

$$
\begin{gathered}
\left(\int_{j \neq i} x_{i, j, i}^{h} d j\right)\left[P^{h}-\left(\rho \cdot H_{i, i, i}^{h}\right)^{\eta}\left(\underline{Q}^{m+h}\right)^{1-\eta}\right]=0, \\
P^{h}-\left(\rho \cdot H_{i, i, i}^{h}\right)^{\eta}\left(\underline{Q}^{m+h}\right)^{1-\eta} \leq 0, \quad \int_{j \neq i} x_{i, j, i}^{h} d j \geq 0
\end{gathered}
$$

(iv) HQs of a multi-location firm, located outside the PBC;

$$
\begin{aligned}
& \left(\int_{z \neq i} \int_{j \neq i} x_{i, j, z}^{h} d j d z\right)\left[P^{h}-\left(K \rho \cdot H_{i, i, i}^{h}\right)^{\eta}\left(\underline{Q}^{m+h}\right)^{1-\eta}\right]=0, \\
& P^{h}-\left(K \rho \cdot H_{i, i, i}^{h}\right)^{\eta}\left(\underline{Q}^{m+h}\right)^{1-\eta} \leq 0, \quad \int_{z \neq i} \int_{j \neq i} x_{i, j, z}^{h} d j d z \geq 0
\end{aligned}
$$

(v) PPs of a multi-location firm, with HQs located in the PBC;

$$
\begin{gathered}
\left(\int_{j \neq i} x_{i, j, i}^{h} d j\right)\left[P^{h}-\left(\rho \cdot \underline{H}^{h}\right)^{\eta}\left(Q_{j}^{m+h}\right)^{1-\eta}\right]=0, \\
P^{h}-\left(\rho \cdot \underline{H}^{h}\right)^{\eta}\left(Q_{j}^{m+h}\right)^{1-\eta} \leq 0, \quad \int x_{i, j, i}^{h} d j \geq 0
\end{gathered}
$$

(vi) PPs of a multi-location firm, with HQs located outside the PBC;

$$
\begin{gathered}
\left(\int_{z \neq i} \int_{j \neq i} x_{i, j, z}^{h} d j d z\right)\left[P^{h}-\left(K \rho \cdot \underline{H}^{h}\right)^{\eta}\left(Q_{j}^{m+h}\right)^{1-\eta}\right]=0, \\
P^{h}-\left(K \rho \cdot \underline{H}^{h}\right)^{\eta}\left(Q_{i}^{m+h}\right)^{1-\eta} \leq 0, \quad \int_{z \neq i} \int_{j \neq i} x_{i, j, z}^{h} d j d z \geq 0
\end{gathered}
$$

where integrals $\int_{z \neq i} \int_{j \neq i} x_{i, j, z}^{h} d j d z, \int_{j \neq i} x_{i, j, i}^{h} d j, \int_{z \neq i} x_{i, i, z}^{h} d j$ aggregate respectively the output of multi-location firms, of multi-location firms with headquarters located in the PBC and of integrated firms located outside the PBC; $K \rho \underline{H}^{h}, K \underline{H}^{h}, \rho \underline{H}^{h}$ and $\underline{Q}^{m+h}$ represent respectively lowest sub-cost functions for stand-alone HQ, for HQ located outside the PBC, for stand-alone HQ located in the PBC and for stand-alone plant. 


\section{B Land developer's maximisation problem}

By Shepard's Lemma:

$$
\begin{aligned}
& l_{i}^{h}=\frac{\partial C_{i, i, i}^{h}}{\partial w_{i}^{h}} \\
& l_{i}^{h}=\eta \mu\left(w_{i}^{h}\right)^{\eta \mu-1}\left(w_{i}^{0}\right)^{\eta(1-\mu)}\left(w_{i}^{m+h}\right)^{1-\eta}\left(l_{i}^{0}\right)^{-\eta \sigma}\left(l_{i}^{m+h}\right)^{-\epsilon(1-\eta)} \\
& \Rightarrow\left(l_{i}^{0}\right)^{-\eta \sigma}\left(l_{i}^{m+h}\right)^{-\epsilon(1-\eta)}=\frac{\left(l_{i}^{h}\right)\left(w_{i}^{h}\right)^{1-\eta \mu}\left(w_{i}^{0}\right)^{\eta(\mu-1)}\left(w_{i}^{m+h}\right)^{\eta-1}}{\eta \mu} ; \\
& l_{i}^{0}=\frac{\partial C_{i, i, i}^{h}}{\partial w_{i}^{0}} \\
& l_{i}^{0}=\eta(1-\mu)\left(w_{i}^{h}\right)^{\eta \mu}\left(w_{i}^{0}\right)^{\eta(1-\mu)-1}\left(w_{i}^{m+h}\right)^{1-\eta}\left(l_{i}^{0}\right)^{-\eta \sigma}\left(l_{i}^{m+h}\right)^{-\epsilon(1-\eta)} \\
& \Rightarrow\left(l_{i}^{0}\right)^{-\eta \sigma}\left(l_{i}^{m+h}\right)^{-\epsilon(1-\eta)}=\frac{\left(l_{i}^{0}\right)\left(w_{i}^{h}\right)^{-\eta \mu}\left(w_{i}^{0}\right)^{1-\eta(1-\mu)}\left(w_{i}^{m+h}\right)^{\eta-1}}{\eta(1-\mu)} ; \\
& l_{i}^{m+h}=\frac{\partial C_{i, i, i}^{h}}{\partial w_{i}^{m+h}} \\
& l_{i}^{m+h}=\eta \gamma\left(w_{i}^{h}\right)^{\eta \mu}\left(w_{i}^{0}\right)^{\eta(1-\mu)}\left(w_{i}^{m+h}\right)^{1-\eta}\left(l_{i}^{0}\right)^{-\eta \sigma}\left(l_{i}^{m+h}\right)^{-\epsilon(1-\eta)} \\
& \Rightarrow\left(l_{i}^{0}\right)^{-\eta \sigma}\left(l_{i}^{m+h}\right)^{-\epsilon(1-\eta)}=\frac{\left(l_{i}^{m+h}\right)\left(w_{i}^{h}\right)^{-\eta \mu}\left(w_{i}^{0}\right)^{\eta(\mu-1)}\left(w_{i}^{m+h}\right)^{\eta}}{1-\eta} ;
\end{aligned}
$$

from (B.1) and (B.2), it follows that

$$
w_{i}^{h} l_{i}^{h}=\frac{\mu}{1-\mu} w_{i}^{0} l_{i}^{0},
$$

while, from (B.2) and (B.3)

$$
w_{i}^{0} l_{i}^{0}=\frac{\eta(1-\mu)}{1-\eta} w_{i}^{m+h} l_{i}^{m+h},
$$

and, then,

$$
\left\{\begin{array}{l}
w_{i}^{h} l_{i}^{h}=\frac{\mu}{1-\mu} w_{i}^{0} l_{i}^{0} \\
w_{i}^{m+h} l_{i}^{m+h}=\frac{1-\eta}{\eta(1-\mu)} w_{i}^{0} l_{i}^{0}
\end{array} .\right.
$$

By (13) we have

$$
w_{i}^{h}=\left(w_{i}^{0}\right)^{-(1-\mu) / \mu}\left[H_{i, i, i}^{h}\left(l_{i}^{0}\right)^{\sigma}\right]^{1 / \mu} ;
$$

now, from (B.7) and, given that $w_{i}^{h} l_{i}^{h}=\sum_{h=1}^{m} w_{i}^{h} l_{i}^{h}$,

$$
\left\{\begin{array}{l}
w_{i}^{0} l_{i}^{0}=\left(\sum_{h=1}^{m} w_{i}^{h} l_{i}^{h}\right) \frac{1-\mu}{\mu} \\
w_{i}^{h}=\left(w_{i}^{0}\right)^{-(1-\mu) / \mu}\left[H_{i, i, i}^{h}\left(l_{i}^{0}\right)^{\sigma}\right]^{1 / \mu} .
\end{array}\right.
$$


We can now manipulate the first equation in (B.8) $)^{28}$ to obtain the total wage bill accruing to 0 -type workers as a function of $l_{i}^{0}$ and $l_{i}^{h}$ :

$$
\begin{array}{r}
w_{i}^{0} l_{i}^{0}=\frac{\left(w_{i}^{0}\right)^{-(1-\mu) / \mu}\left(l_{i}^{0}\right)^{\sigma / \mu}\left[\sum_{h=1}^{m}\left(H_{i, i, i}^{h}\right)^{1 / \mu} l_{i}^{h}\right]}{\mu /(1-\mu)} \\
\Rightarrow\left(w_{i}^{0} l_{i}^{0}\right)^{\mu}=[(1-\mu) / \mu]^{\mu}\left(w_{i}^{0}\right)^{(\mu-1)}\left(l_{i}^{0}\right)^{\sigma}\left[\sum_{h=1}^{m}\left(H_{i, i, i}^{h}\right)^{1 / \mu} l_{i}^{h}\right]^{\mu} \\
\Rightarrow w_{i}^{0}\left(l_{i}^{0}\right)^{\mu}=[(1-\mu) / \mu]^{\mu}\left(l_{i}^{0}\right)^{\sigma}\left[\sum_{h=1}^{m}\left(H_{i, i, i}^{h}\right)^{1 / \mu} l_{i}^{h}\right]^{\mu} \\
\Rightarrow w_{i}^{0}\left(l_{i}^{0}\right)^{\mu}\left(l_{i}^{0}\right)^{1-\mu}=[(1-\mu) / \mu]^{\mu}\left(l_{i}^{0}\right)^{\sigma}\left(l_{i}^{0}\right)^{1-\mu}\left[\sum_{h=1}^{m}\left(H_{i, i, i}^{h}\right)^{1 / \mu} l_{i}^{h}\right]^{\mu} \\
\Rightarrow w_{i}^{0} l_{i}^{0}=[\mu / 1-\mu]^{-\mu} \underbrace{\left(l_{i}^{0}\right)^{1+\sigma-\mu} H_{i, i}\left(\sum_{h=1}^{m} l_{i}^{h}\right)^{\mu}}_{\psi} .
\end{array}
$$

then, substituting (B.4) ${ }^{29}$ into (B.9), and remembering that $\sum_{h=0}^{m+1} w_{i}^{h} l_{i}^{h}=\left(\sum_{h=1}^{m} w_{i}^{h} l_{i}^{h}\right)+w_{i}^{0} l_{i}^{0}$, we get

$$
\sum_{h=0}^{m} w_{i}^{h} l_{i}^{h}=\mu^{-\mu}(1-\mu)^{-(1-\mu)} \psi
$$

We can now define the maximisation problem of this component, that is, the LD's programme for given $\sum_{h=0}^{m} l_{i}^{h}$ writes as:

$$
\begin{gathered}
\max _{\left\{l_{i}^{0}, l_{i}^{h}\right\}} \sum_{h=0}^{m} w_{i}^{h} l_{i}^{h}=\mu^{-\mu}(1-\mu)^{-(1-\mu)}\left(l_{i}^{0}\right)^{1+\sigma-\mu} H_{i, i}\left(\sum_{h=1}^{m} l_{i}^{h}\right)^{\mu}, \\
\text { s.t } \sum_{h=0}^{m} l_{i}^{h}=Z .
\end{gathered}
$$

where $Z$ is a constant. Note that $Z=\left(\sum_{h=1}^{m} l_{i}^{h}\right)+l_{i}^{0} \Rightarrow \sum_{h=1}^{m} l_{i}^{h}=Z-l_{i}^{0}$. Define now: $\Delta=\mu^{-\mu}(1-\mu)^{-(1-\mu)} H_{i, i}$; then, using $\quad \sum_{h=1}^{m} l_{i}^{h}=Z-l_{i}^{0} \quad$ and taking the $\mu$-root, the maximand becomes:

$$
\Delta^{\frac{1}{\mu}} Z\left(l_{i}^{0}\right)^{\frac{1+\sigma-\mu}{\mu}}-\Delta^{\frac{1}{\mu}}\left(l_{i}^{0}\right)^{\frac{1+\sigma}{\mu}} .
$$

by manipulating the first derivative with respect to $l_{i}^{0}$ we get the following relation between the i-city HQ and ABS specific workforces:

$$
\frac{\partial \sum_{h=0}^{m} w_{i}^{h} l_{i}^{h}}{\partial l_{i}^{0}}=0 \Rightarrow \sum_{h=1}^{m} l_{i}^{h}=\frac{\mu}{(1+\theta)(1-\mu)} l_{i}^{0}=\frac{\mu}{1+\sigma-\mu} l_{i}^{0} .
$$

Then, by substituting (B.13) in the maximand (B.11), we get

$$
\sum_{h=0}^{m} w_{i}^{h} l_{i}^{h}=\frac{(1+\theta)^{-\mu}}{1-\mu} H_{i, i}\left(l_{i}^{0}\right)^{1+\theta(1-\mu)} ;
$$

\footnotetext{
${ }^{28}$ Note that the last step is allowed since profit maximisation by LD requires $H_{i, i, i}^{h}=H_{i, i}$ for all $h$ such that $l_{i}^{h} \geq 0$.

${ }^{29}$ Note that $\sum_{h=1}^{m} w_{i}^{h} l_{i}^{h}=w_{i}^{h} l_{i}^{h}$.
} 
and, from (13)

$$
\sum_{h=1}^{m} w_{i}^{m+h} l_{i}^{m+h}=\sum_{h=1}^{m} Q_{i}^{m+h}\left(l_{i}^{m+h}\right)^{1+\epsilon}
$$

We can now substitute the latter two summations into the developer programme of (18)

$$
\Pi_{i}=\sum_{h=0}^{m} w_{i}^{h} l_{i}^{h}+Q_{i}^{m+h}\left(l_{i}^{m+h}\right)^{1+\epsilon}-L_{i} \bar{e},
$$

so that the LD's objective function writes as

$$
\max _{\left\{l_{i}^{0}, l_{i}^{h}, l_{i}^{m+h}\right\}} \Pi_{i}, \quad \Pi_{i}=\frac{(1+\theta)^{-\mu}}{1-\mu} H_{i, i}\left(l_{i}^{0}\right)^{1+\theta(1-\mu)}+Q_{i, i}^{m+h}\left(l_{i}^{m+h}\right)^{1+\epsilon}-L_{i} \bar{e} .
$$

\section{City sizes (Proof of Lemma 2)}

The proof of Lemma with respect to the cases (a), (c), and (d) traces back to Duranton and Puga (2004) and Duranton and Puga (2005).

\section{C.1 Case (b)}

Consider a city hosting only headquarters of multi-location firms, the equilibrium unit production cost for firms in sector $h$ is:

$$
c_{b}^{h}=(\rho \cdot K)^{\eta}\left(w_{b}^{h}\right)^{\eta \mu}\left(w_{b}^{0}\right)^{\eta(1-\mu)}\left(w_{b}^{m+h}\right)^{1-\eta}\left(l_{b}^{0}\right)^{-\eta \sigma}\left(l_{b}^{m+h}\right)^{-\epsilon(1-\eta)}
$$

By Shepard's Lemma:

$$
w_{b}^{0}=\frac{(1-\mu) w_{b}^{h} l_{b}^{h}}{\mu l_{b}^{0}}
$$

Substituting (C.2) into (C.1) yields:

$$
c_{b}^{h}=(\rho \cdot K)^{\eta}\left[w_{b}^{m+h}\left(l_{b}^{m+h}\right)^{-\epsilon}\right]^{(1-\eta)}\left(w_{b}^{h}\right)^{\eta}\left(\frac{1-\mu}{\mu}\right)^{\eta(1-\mu)}\left(l_{b}^{0}\right)^{-\eta(1-\mu+\sigma)}\left(l_{b}^{h}\right)^{\eta(1-\mu)}
$$

then, given that $c_{b}^{h}=P^{h}$ :

$$
\sum_{h=0}^{2 m} w_{b}^{h} l_{b}^{h}=w_{b}^{h} l_{b}^{h}=\left\{\frac{P^{h}(\mu)^{\eta(1-\mu)}\left(l_{b}^{0}\right)^{\eta(1-\mu+\sigma)}\left(l_{b}^{h}\right)^{\eta \mu}}{(\rho \cdot K)^{\eta}\left[w_{b}^{m+h}\left(l_{b}^{m+h}\right)^{-\epsilon}\right]^{(1-\eta)}\left(w_{b}^{h}\right)^{\eta}(1-\mu)^{\eta(1-\mu)}}\right\}^{1 / \eta}
$$

and,

$$
l_{b}^{h}=L_{b}^{h}\left(1-\tau L_{b}^{h}\right)
$$

so as:

$$
\operatorname{Max}_{l_{b}^{h}, l_{b}^{m+h}} \Pi_{b}, \quad \Pi_{b}=\left\{\frac{P^{h}(\mu)^{\eta(1-\mu)}\left(l_{b}^{0}\right)^{\eta(1-\mu+\sigma)}\left(l_{b}^{h}\right)^{\eta \mu}}{(\rho \cdot K)^{\eta}\left[w_{b}^{m+h}\left(l_{b}^{m+h}\right)^{-\epsilon}\right]^{(1-\eta)}\left(w_{b}^{h}\right)^{\eta}(1-\mu)^{\eta(1-\mu)}}\right\}^{1 / \eta}-L_{b}^{h} \bar{e}
$$

subject to (C.5), is the equivalent developer's programme of (18). First order conditions for (C.6) together with (C.5) and $\Pi_{b}^{h}=0$ yield equilibrium population for any city hosting only headquarters as:

$$
L_{b}=\frac{1+\mu}{\tau(1+2 \mu)}
$$




\section{C.2 Case (e)}

Consider a city hosting only integrated firms and intermediates suppliers, the equilibrium unit production cost for firms in sector $h$ is:

$$
c_{e}^{h}=K^{\eta}\left(w_{e}^{h}\right)^{\eta \mu}\left(w_{e}^{0}\right)^{\eta(1-\mu)}\left(w_{e}^{m+h}\right)^{1-\eta}\left(l_{e}^{0}\right)^{-\eta \sigma}\left(l_{e}^{m+h}\right)^{-\epsilon(1-\eta)}
$$

By Shepard's Lemma ${ }^{30}$ :

$$
w_{e}^{0} l_{e}^{0}=\frac{1-\mu}{\mu} w_{e}^{h} l_{e}^{h}=\frac{\eta(1-\mu)}{1-\eta} w_{e}^{m+h} l_{e}^{m+h}
$$

By Shepard's Lemma and (B.13):

$$
w_{e}^{0}=\frac{w_{e}^{h}}{1+\theta}, \quad w_{e}^{h}=\frac{\eta \mu}{1-\eta} \frac{w_{e}^{m+h} l_{e}^{m+h}}{l_{e}^{h}}
$$

Substituting (C.10) into (C.8) yields:

$$
c_{e}^{h}=w_{e}^{m+h} l_{e}^{m+h} K^{\eta}(1+\theta)^{-\eta(1-\mu)}\left(l_{e}^{0}\right)^{-\eta \sigma}\left(l_{e}^{h}\right)^{-\eta)}\left(l_{e}^{m+h}\right)^{(-\epsilon(1-\eta)-1}
$$

then, given that $c_{e}^{h}=P^{h}$ :

$$
\begin{array}{r}
\sum_{h=0}^{2 m} w_{e}^{h} l_{e}^{h}=w_{e}^{h} l_{e}^{h}+w_{e}^{m+h} l_{e}^{m+h}=\frac{-\mu}{(1-\eta)} w_{e}^{m+h} l_{e}^{m+h}= \\
=\frac{(1-\eta) P^{h}\left(l_{e}^{0}\right)^{\eta \sigma}\left(l_{e}^{h}\right)^{\eta}\left(l_{e}^{m+h}\right)^{1+\epsilon(1-\eta)}}{-\mu K^{n}(1+\theta)^{\eta(1-\mu)}}
\end{array}
$$

and,

$$
l_{e}^{h}+l_{e}^{m+h}=L_{e}^{h}\left(1-\tau L_{e}^{h}\right)
$$

so as:

$$
\operatorname{Max}_{l_{e}^{h}} \Pi_{e}, \quad \Pi_{e}=\frac{(1-\eta) P^{h}\left(l_{e}^{0}\right)^{\eta \sigma}\left(l_{e}^{h}\right)^{\eta}\left(l_{e}^{m+h}\right)^{1+\epsilon(1-\eta)}}{-\mu K^{n}(1+\theta)^{\eta(1-\mu)}}-L_{e}^{h} \bar{e}
$$

subject to (C.13), is the equivalent developer's programme of (18). First order conditions for (C.14) together with (C.13) and $\Pi_{e}^{h}=0$ yield equilibrium population for any city hosting only headquarters as:

$$
L_{e}=\frac{\epsilon(1-\eta)}{\tau[1+2 \epsilon(1-\eta)]}
$$

Total population then splits between occupations as:

$$
\begin{aligned}
l_{e}^{h} & =\frac{\eta}{1+\epsilon(1-\eta)} L_{e}^{h}\left(1-\tau L_{e}\right) \\
l_{e}^{m+h} & =\frac{(1+\epsilon)(1-\eta)}{1+\epsilon(1-\eta)} L_{e}^{h}\left(1-\tau L_{e}\right)
\end{aligned}
$$

\footnotetext{
${ }^{30}$ See (B.6).
} 


\section{C.3 Case (f)}

Consider a city hosting only business service providers, the equilibrium unit production cost for a multi-location (or integrated ${ }^{31}$ ) firm in sector $h$ buying business services from that city is:

$$
c_{f}^{h}=(\rho \cdot K)^{\eta}\left(w_{f}^{h}\right)^{\eta \mu}\left(w_{f}^{0}\right)^{\eta(1-\mu)}\left(w_{f}^{m+h}\right)^{1-\eta}\left(l_{f}^{0}\right)^{-\eta \sigma}\left(l_{f}^{m+h}\right)^{-\epsilon(1-\eta)}
$$

From (B.6):

$$
w_{f}^{h}=\frac{\mu w_{f}^{0} l_{f}^{0}}{(1-\mu) l_{f}^{h}}
$$

Substituting (C.19) into (C.18) yields:

$$
c_{f}^{h}=(\rho \cdot K)^{\eta}\left(w_{f}^{0}\right)^{(1-\mu) \eta}\left(l_{f}^{0}\right)^{-\eta \sigma}\left(w_{f}^{m+h}\right)^{1-\eta}\left(l_{f}^{m+h}\right)^{-\epsilon(1-\eta)}\left(w_{f}^{h}\right)^{\mu \eta}
$$

then, given that $c_{f}^{h}=P^{h}$ :

$$
\sum_{h=0}^{2 m} w_{f}^{h} l_{f}^{h}=w_{f}^{0} l_{f}^{0}=\left\{\frac{P^{h}\left(l_{f}^{0}\right)^{\eta(1-\mu+\sigma)}\left(l_{f}^{m+h}\right)^{\epsilon(1-\eta)}}{(\rho \cdot K)^{\eta}\left(w_{f}^{h}\right)^{\mu \eta}\left(w_{f}^{m+h}\right)^{1-\eta}}\right\}^{1 / \eta(1-\mu)}
$$

and,

$$
l_{f}^{0}=L_{f}^{h}\left(1-\tau L_{f}^{h}\right)
$$

so as:

$$
\operatorname{Max}_{l_{f}^{0}} \Pi_{f}, \quad \Pi_{f}=\left\{\frac{P^{h}\left(l_{f}^{0}\right)^{\eta(1-\mu+\sigma)}\left(l_{f}^{m+h}\right)^{\epsilon(1-\eta)}}{(\rho \cdot K)^{\eta}\left(w_{f}^{h}\right)^{\mu \eta}\left(w_{f}^{m+h}\right)^{1-\eta}}\right\}^{1 / \eta(1-\mu)}-L_{f}^{h} \bar{e}
$$

subject to (C.22), is the equivalent developer's programme of (18). First order conditions for (C.23) together with (C.22) and $\Pi_{f}^{h}=0$ yield equilibrium population for any city hosting only headquarters as:

$$
L_{f}=\frac{\sigma}{\tau[1-\mu+2 \sigma]}
$$

\section{Thresholds (Proof of Proposition 1)}

\section{D.1 From spatial configuration 1 to 2}

The equilibrium unit production cost for multi-location firms with headquarters co-located with business service providers is:

$$
c_{a}^{h}=(\rho)^{\eta}\left(w_{a}^{h}\right)^{\eta \mu}\left(w_{a}^{0}\right)^{\eta(1-\mu)}\left(w_{c}^{m+h}\right)^{1-\eta}\left(l_{a}^{0}\right)^{-\eta \sigma}\left(l_{c}^{m+h}\right)^{-\epsilon(1-\eta)}
$$

Dividing this by the unit production cost for fully integrated firms yields:

$$
\frac{c_{a}^{h}}{c_{d}^{h}}=\left(\frac{\rho}{\hat{\rho}}\right)^{\eta}
$$

\footnotetext{
${ }^{31}$ In this case $(\rho \cdot K)^{\eta}$ should be replaced by $K^{\eta}$, yelding the same results.
} 
where:

$$
\hat{\rho}=\left[\left(\frac{w_{d}^{h}}{w_{a}^{h}}\right)^{\eta \mu}\left(\frac{w_{d}^{0}}{w_{a}^{0}}\right)^{\eta(1-\mu)}\left(\frac{w_{d}^{m+h}}{w_{c}^{m+h}}\right)^{1-\eta}\left(\frac{l_{d}^{0}}{l_{a}^{0}}\right)^{-\eta \sigma}\left(\frac{l_{d}^{m+h}}{l_{c}^{m+h}}\right)^{-\epsilon(1-\eta)}\right]^{\frac{1}{\eta}}
$$

By Shepard's Lemma and (B.13):

$$
\frac{w_{a}^{h}}{w_{a}^{0}}=1+\theta ; \quad \frac{w_{a}^{m+h}}{w_{a}^{0}}=\frac{(1-\eta) l_{a}^{0}}{\eta(1-\mu) l_{a}^{m+h}}
$$

The developer programme of (18), together with the exhaustion of developers' profits due to free entry imply:

$$
\frac{1}{\eta(1-\mu)} w_{d}^{0} l_{d}^{0}=L_{d} \bar{e} ; \quad \frac{1}{1-\mu} w_{a}^{0} l_{a}^{0}=L_{a} \bar{e} ; \quad w_{c}^{m+h} l_{c}^{m+h}=L_{c} \bar{e}
$$

From (D.4) and (D.5),

$$
\frac{w_{d}^{h}}{w_{a}^{h}}=\frac{w_{d}^{0}}{w_{a}^{0}}=\frac{\eta L_{d} l_{a}^{0}}{L_{a} l_{d}^{0}} ; \quad \frac{w_{d}^{m+h}}{w_{c}^{m+h}}=\frac{(1-\eta) L_{d} l_{c}^{m+h}}{L_{c} l_{d}^{m+h}}
$$

Then, from $\sum_{h=0}^{2 m} l_{i}^{h}=L_{i}\left(1-\tau L_{i}\right)$ and (B.13):

$$
\begin{gathered}
l_{a}^{0}=\frac{1+\sigma-\mu}{1+\sigma} L_{a}^{h}\left(1-\tau L_{a}^{h}\right) \\
l_{c}^{m+h}=L_{c}\left(1-\tau L_{c}\right)
\end{gathered}
$$

while, from Lemma 2,

$$
\begin{gathered}
l_{d}^{0}=\frac{\eta(1+\sigma-\mu)}{1+\gamma} L_{d}^{h}\left(1-\tau L_{d}^{h}\right) \\
l_{d}^{m+h}=\frac{(1-\eta)(1+\epsilon)}{1+\gamma} L_{d}^{h}\left(1-\tau L_{d}^{h}\right)
\end{gathered}
$$

Substituting (D.6), (D.7), (D.8), (D.9), (D.10) and Lemma 2 into (D.3) and simplifying yields the value of $\hat{\rho}$ given in the proposition. When $\rho<\hat{\rho}$, and if no other functional specialisation trend is present, total mass of cities split between cities of type (a) and type (c). We denote by $N_{a}$ the mass of cities that host headquarters of multi-location firms plus advanced business services and by $N_{c}$ the mass of cities that host production plants of multi-location firms. By Shepard's Lemma,

$$
\frac{w_{a}^{0} l_{a}^{0} N_{a}}{w_{c}^{m+h} l_{c}^{m+h} N_{c}}=\frac{\eta(1-\mu)}{1-\eta}
$$

Combining this with (D.6) yields the share of cities hosting only headquarters of multi-location firms plus advanced business services when $\rho<\hat{\rho}$ as

$$
\frac{\eta \epsilon(1+2 \sigma)}{\eta \epsilon(1+2 \sigma)+(1-\eta) \sigma(1+2 \epsilon)}
$$

Remaining cities specialise in production and, by symmetry, there are equal proportions of cities specialised in each of the $m$ sectors. 


\section{D.2 From spatial configuration 1 to 3}

The equilibrium unit production cost for integrated firms buying business services from abroad is:

$$
c_{e}^{h}=(K)^{\eta}\left(w_{e}^{h}\right)^{\eta \mu}\left(w_{f}^{0}\right)^{\eta(1-\mu)}\left(w_{e}^{m+h}\right)^{1-\eta}\left(l_{f}^{0}\right)^{-\eta \sigma}\left(l_{e}^{m+h}\right)^{-\epsilon(1-\eta)}
$$

Dividing this by the unit production cost for fully integrated firms yields:

$$
\frac{c_{e}^{h}}{c_{d}^{h}}=\left(\frac{K}{\hat{K}}\right)^{\eta}
$$

where:

$$
\hat{K}=\left[\left(\frac{w_{d}^{h}}{w_{e}^{h}}\right)^{\eta \mu}\left(\frac{w_{d}^{0}}{w_{f}^{0}}\right)^{\eta(1-\mu)}\left(\frac{w_{d}^{m+h}}{w_{e}^{m+h}}\right)^{1-\eta}\left(\frac{l_{d}^{0}}{l_{f}^{0}}\right)^{-\eta \sigma}\left(\frac{l_{d}^{m+h}}{l_{e}^{m+h}}\right)^{-\epsilon(1-\eta)}\right]^{\frac{1}{\eta}}
$$

By Shepard's Lemma,

$$
\frac{w_{d}^{0}}{w_{d}^{h}}=\frac{1-\mu}{\mu} \frac{l_{d}^{h}}{l_{d}^{0}}
$$

The developer programme of (18), together with the exhaustion of developers' profits due to free entry imply:

$$
\begin{aligned}
w_{d}^{h} l_{d}^{h}=\eta \mu L_{d} \bar{e} ; \quad w_{f}^{0} l_{f}^{0} & =L_{f} \bar{e} ; \quad w_{e}^{m+h} l_{e}^{m+h}=\frac{1-\eta}{1-\eta+\mu \eta} L_{e} \bar{e} ; \\
w_{d}^{m+h} l_{d}^{m+h} & =(1-\eta) L_{d} \bar{e} ; \quad w_{e}^{h} l_{e}^{h}=\frac{\mu \eta}{1-\eta+\mu \eta} L_{e} \bar{e} ; \quad w_{d}^{0} l_{d}^{0}=\eta(1-\mu) L_{d} \bar{e}
\end{aligned}
$$

From (D.14) and (D.15),

$$
\frac{w_{d}^{h}}{w_{e}^{h}}=\frac{[1-\eta(1-\mu)] L_{d} l_{e}^{h}}{L_{e} l_{d}^{h}} ; \quad \frac{w_{d}^{m+h}}{w_{e}^{m+h}}=\frac{[1-\eta(1-\mu)] L_{d} l_{e}^{m+h}}{L_{e} l_{d}^{m+h}} ; \quad \frac{w_{d}^{0}}{w_{f}^{0}}=\frac{\eta(1-\mu) L_{d}\left(1-\tau L_{f}\right)}{l_{d}^{0}}
$$

Then, from $\sum_{h=0}^{2 m} l_{i}^{h}=L_{i}\left(1-\tau L_{i}\right)$ and (B.13):

$$
l_{f}^{0}=L_{f}\left(1-\tau L_{f}\right)
$$

Substituting (D.9), (D.10),(D.16), (D.17) and Lemma 2 into (D.13) and simplifying yields the value of $\hat{K}$ given in the proposition. When $K<\hat{K}$,and if no other functional specialisation trend is present, total mass of cities split between cities of type (e) and type (f).

\section{D.3 From spatial configuration 3 to 4}

The equilibrium unit production cost for firms adopting multi-location of (17) is:

$$
c_{b}^{h}=(\rho \cdot K)^{\eta}\left(w_{b}^{h}\right)^{\eta \mu}\left(w_{f}^{0}\right)^{\eta(1-\mu)}\left(w_{c}^{m+h}\right)^{1-\eta}\left(l_{f}^{0}\right)^{-\eta \sigma}\left(l_{c}^{m+h}\right)^{-\epsilon(1-\eta)}
$$

Dividing this by the unit production cost for partially integrated ex-CD firms yields:

$$
\frac{c_{b}^{h}}{c_{e}^{h}}=\left(\frac{\rho}{\bar{\rho}}\right)^{\eta}
$$


where:

$$
\bar{\rho}=\left[\left(\frac{w_{e}^{h}}{w_{b}^{h}}\right)^{\eta \mu}\left(\frac{w_{e}^{m+h}}{w_{c}^{m+h}}\right)^{1-\eta}\left(\frac{l_{e}^{m+h}}{l_{c}^{m+h}}\right)^{-\epsilon(1-\eta)}\right]^{\frac{1}{\eta}}
$$

By Shepard's Lemma we have that $w_{e}^{h} l_{e}^{h}=\frac{\mu \eta}{1-\eta} w_{e}^{m+h} l_{e}^{m+h}$ and,

$$
\frac{w_{e}^{h}}{w_{e}^{m+h}}=\frac{\mu \eta}{1-\eta} \frac{l_{e}^{m+h}}{l_{e}^{h}}
$$

The developer programme of (18), together with the exhaustion of developers' profits due to free entry, implies:

$$
w_{b}^{h} l_{b}^{h}=L_{b} \bar{e} ; \quad w_{c}^{m+h} l_{c}^{m+h}=L_{c} \bar{e} ; \quad w_{e}^{m+h} l_{e}^{m+h}=\frac{1-\eta}{1-\eta+\mu \eta} L_{e} \bar{e}
$$

From (D.21), (D.22),

$$
w_{e}^{h}=\frac{\mu \eta}{1-\eta+\mu \eta} \frac{L_{e} \bar{e}}{l_{e}^{h}}
$$

From (D.21), (D.22), (D.23),

$$
\frac{w_{e}^{h}}{w_{b}^{h}}=\frac{\mu \eta}{1-\eta+\mu \eta} \frac{L_{e}\left(1-\tau L_{b}\right)}{l_{e}^{h}} ; \quad \frac{w_{e}^{m+h}}{w_{c}^{m+h}}=\frac{1-\eta}{1-\eta+\mu \eta} \frac{L_{e}\left(1-\tau L_{c}\right)}{l_{e}^{m+h}} ;
$$

Substituting (C.17), (D.8) and Lemma 2 into (D.20) and simplifying yields the value of $\bar{\rho}$ given in the proposition. When $\rho<\bar{\rho}$, total mass of cities split between cities of type (b), type (f) and type (c).

\section{D.4 From spatial configuration 2 to 4}

Dividing the equilibrium unit production cost of (D.18) by the equilibrium unit production cost for firms adopting multi-location organisational form of (16) yields:

$$
\frac{c_{b}^{h}}{c_{a}^{h}}=\left(\frac{K}{\bar{K}}\right)^{\eta}
$$

where:

$$
\bar{K}=\left[\left(\frac{w_{a}^{h}}{w_{b}^{h}}\right)^{\eta \mu}\left(\frac{w_{a}^{0}}{w_{f}^{0}}\right)^{\eta(1-\mu)}\left(\frac{l_{a}^{0}}{l_{f}^{0}}\right)^{-\eta \sigma}\right]^{\frac{1}{\eta}}
$$

The developer programme of (18), together with the exhaustion of developers' profits due to free entry imply:

$$
w_{a}^{0} l_{a}^{0}=(1-\mu) L_{a} \bar{e} ; \quad w_{a}^{h} l_{a}^{h}=\mu L_{a} \bar{e} ; \quad w_{b}^{h} l_{b}^{h}=L_{b} \bar{e} ; \quad w_{f}^{h} l_{b}^{f}=L_{f} \bar{e}
$$

From (D.27),

$$
\frac{w_{a}^{h}}{w_{b}^{h}}=\mu \frac{L_{a}\left(1-\tau L_{b}\right)}{l_{a}^{h}} ; \quad \frac{w_{a}^{0}}{w_{f}^{0}}=(1-\mu) \frac{L_{a}\left(1-\tau L_{f}\right)}{l_{a}^{0}}
$$

Again, from $\sum_{h=0}^{2 m} l_{i}^{h}=L_{i}\left(1-\tau L_{i}\right)$ and Lemma 2,

$$
l_{a}^{h}=\frac{\mu}{1+\sigma} L_{a}^{h}\left(1-\tau L_{a}^{h}\right)
$$

Substituting (D.7), (D.17), (D.29) and Lemma 2 into (D.25) and simplifying yields the value of $\bar{K}$ given in the proposition. When $K<\bar{K}$, total mass of cities split between cities of type (b), type (f) and type (c). 


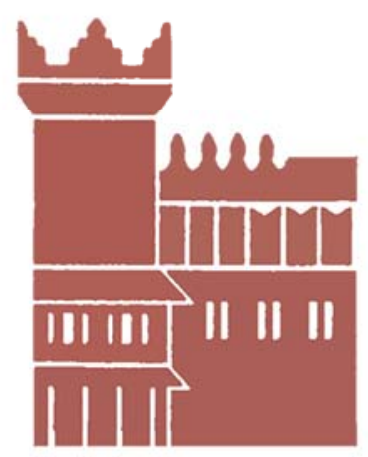

Alma Mater Studiorum - Università di Bologna DEPARTMENT OF ECONOMICS

Strada Maggiore 45

40125 Bologna - Italy

Tel. +39051 2092604

Fax +390512092664

http://www.dse.unibo.it 